\title{
Desert dust and anthropogenic aerosol interactions in the Community Climate System Model coupled-carbon-climate model
}

\author{
N. Mahowald ${ }^{1}$, K. Lindsay ${ }^{2}$, D. Rothenberg ${ }^{1}$, S. C. Doney ${ }^{3}$, J. K. Moore ${ }^{4}$, P. Thornton ${ }^{5}$, J. T. Randerson ${ }^{4}$, and \\ C. D. Jones 6 \\ ${ }^{1}$ Department of Earth and Atmospheric Sciences, Cornell University, Ithaca, NY, 14853, USA \\ ${ }^{2}$ Climate and Global Dynamics Division, National Center for Atmospheric Research, Boulder, CO, 80305, USA \\ ${ }^{3}$ Department of Marine Chemistry and Geochemistry, Woods Hole Oceanographic Institution, Woods Hole, MA 02543, USA \\ ${ }^{4}$ Department of Earth System Science, University of California, Irvine, CA 92697, USA \\ ${ }^{5}$ Environmental Sciences Division, Oak Ridge National Laboratory, Oak Ridge, TN 37831, USA \\ ${ }^{6}$ Meteorological Office, Hadley Center, Exeter, EX1 3PB, UK
}

Received: 30 July 2010 - Published in Biogeosciences Discuss.: 1 September 2010

Revised: 7 January 2011 - Accepted: 28 January 2011 - Published: 15 February 2011

\begin{abstract}
Coupled-carbon-climate simulations are an essential tool for predicting the impact of human activity onto the climate and biogeochemistry. Here we incorporate prognostic desert dust and anthropogenic aerosols into the CCSM3.1 coupled carbon-climate model and explore the resulting interactions with climate and biogeochemical dynamics through a series of transient anthropogenic simulations (20th and 21st centuries) and sensitivity studies. The inclusion of prognostic aerosols into this model has a small net global cooling effect on climate but does not significantly impact the globally averaged carbon cycle; we argue that this is likely to be because the CCSM3.1 model has a small climate feedback onto the carbon cycle. We propose a mechanism for including desert dust and anthropogenic aerosols into a simple carbon-climate feedback analysis to explain the results of our and previous studies. Inclusion of aerosols has statistically significant impacts on regional climate and biogeochemistry, in particular through the effects on the ocean nitrogen cycle and primary productivity of altered iron inputs from desert dust deposition.
\end{abstract}

\section{Introduction}

Estimating the impact of humans onto the climate system through the 21 st century requires an understanding of the physical response of the climate system to changes in

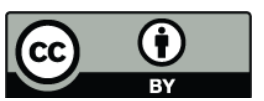

Correspondence to: N. Mahowald (mahowald@ucar.edu) greenhouse gases and aerosols and the climate feedbacks via changes in carbon uptake by the land and the ocean system (Denman et al., 2007). Approximately 50\% of the carbon emitted by humans into the atmosphere is taken up by the land or ocean (Denman et al., 2007), but the effectiveness of land and ocean carbon sinks is projected to decline under future climate change scenarios (e.g. Cox et al., 2000; Fung et al., 2005). The uncertainties in the response of the land and ocean carbon cycle represent uncertainties almost as large as those from climate sensitivity when considering climate at 2100 (Huntingford et al., 2009).

There are significant uncertainties in carbon trajectories even given a particular human $\mathrm{CO}_{2}$ emission scenario (e.g. Friedlingstein et al., 2006; Huntingford et al., 2009). Most of the coupled carbon-climate model simulations up to this point have been based on terrestrial carbon cycle models that do not include the limitation by nitrogen (e.g. Cox et al., 2000; Friedlingstein et al., 2006; Denman et al., 2007)). These same models tend to see a positive feedback of climate onto the carbon cycle; higher carbon dioxide in the atmosphere leads to climate change that reduces the ability of the land and ocean to take up carbon (Friedlingstein et al., 2006). Terrestrial carbon cycle models that include $\mathrm{N}$-colimitation, including the one used here, tend to see a much reduced terrestrial carbon uptake, and a reduced climate feedback onto carbon (e.g. Sokolov et al., 2008; Thornton et al., 2009; Zaehle et al., 2010). Thus, the inclusion of a new process into the coupled-carbon-climate models has the potential to fundamentally change the simulated response of the carbon cycle to climate. 
Anthropogenic and natural aerosols represent an additional process that has not yet been fully incorporated into coupled carbon-climate models. Aerosols are solids or liquids suspended in the atmosphere. They interfere with incoming and outgoing radiation, and potentially impact cloud formation (e.g. Forster et al., 2007). Sulfate and volcanic aerosols have been implemented in one coupled-carbon cycle model, resulting in a substantial change in the projections of future climate (Jones et al., 2003). Other simulations included have included only partially coupled carbon cycle (Stier et al., 2006) with no interactive land carbon cycle. The coupled carbon cycle model used for the previous study (Jones et al., 2003) has a very strong response to climate, both because of a high climate sensitivity, as well as a large sensitivity of the carbon cycle to climate change (e.g. Cox et al., 2000; Friedlingstein et al., 2006). Here we look at the role of sulfate and volcanic aerosols, as well as other anthropogenic aerosols (black and organic carbon aerosols from combustion) (Jones et al., 2003 included sulfate aerosols, ozone and other greenhouse gas changes). Since our model has a much smaller climate-carbon feedback (Thornton et al., 2009), we expect to see quite different results than the (Jones et al., 2003) study.

In addition, we include for the first time that we are aware of prognostic desert dust aerosols in a coupled carbonclimate model. Desert dust, or mineral aerosols, are soil particles suspended in the atmosphere. In addition to the physical climate forcings similar to other aerosols, desert dust contains small amounts of iron (3.5\%), which is an important micronutrient for the oceans (e.g. Martin et al., 1991). Thus, changes in desert dust deposition to the oceans may impact the ability of the ocean to take up carbon dioxide (e.g. J. K. Moore et al., 2006). The ocean biota may be directly iron limited (e.g. Martin et al., 1991), or the iron from dust may encourage more nitrogen fixation (e.g. Falkowski et al., 1998), thus impacting the nitrogen cycle of the ocean (Krishnamurty et al., 2009). While desert dust is known to be sensitive to climate and land use (e.g. Kohfeld and Harrison, 2001; Prospero and Lamb, 2003; Gillette, 1988; Neff et al., 2005), it is unclear whether desert dust is increasing or decreasing due to humans (e.g. Tegen and Fung, 1995; Prospero et al., 2002; Tegen et al., 2004; Mahowald and Luo, 2003; Mahowald et al., 2004, 2009). The estimates range from changes of $-25 \%$ to $+60 \%$ (Mahowald et al., 2009) from preindustrial to present conditions and are even larger going into the future (e.g. Mahowald and Luo, 2003; Tegen et al., 2004; Woodward et al., 2005). Recent estimates suggest roughly a doubling in dust over the last 100 years (Mahowald et al., 2010; Mulitza et al., 2010). Therefore we include sensitivity studies with different changes in desert dust sources.

We also explore the sensitivity of the transient responses of the coupled-carbon-climate model to changes in the initial conditions, in particular examining how close to equilibrium we need to establish the model for robust climate change sim- ulations. In addition we conduct sensitivity studies comparing cases where the atmospheric carbon dioxide is predicted prognostically (and thus allowing for $\mathrm{CO}_{2}$ gradients in the vertical and horizontal) against cases where the atmospheric carbon dioxide is specified as single globally averaged concentration value, as required for the next IPCC (Taylor et al., 2009).

\section{Methods}

\subsection{Model description}

Our model is the coupled-carbon-climate model used in (Thornton et al., 2009), which is based on the Community Climate System Model (CCSM3) (Collins et al., 2006a). This model has atmospheric, ocean, land and sea ice components, linked together using a coupler. The terrestrial biosphere model is the Community Land Model-Carbon Nitrogen (CLM-CN) model, described in (Thornton et al., 2007, 2009) and evaluated in (Randerson et al., 2009). This model includes N-limitation of plant growth. The ocean biogeochemistry model is the Biogeochemical Element Cycling (BEC) model which includes four functional phytoplankton groups and multiple growth-limiting nutrients (Moore et al., 2004) and a full depth carbon-cycle module (Doney et al., 2006). In the BEC model, nitrogen fixing organisms in the oceans require more iron than most phytoplankton (Falkowski et al., 1998), thus linking the iron and nitrogen budgets in the ocean (J. K. Moore et al., 2006). This model has been extensively compared to available observations (Doney et al., 2009a, b). The impact of iron deposition in dust, and the changes in soluble iron over the 20th century that may have occurred (Mahowald et al., 2009) have previously been shown in this model to impact ocean biogeochemistry and the nitrogen cycle more than direct human deposition of nitrogen (Krishnamurty et al., 2009)

In some of the model experiments conducted, desert dust is coupled using the desert dust model previously developed for the CCSM3 (Mahowald et al., 2006a). The desert dust is produced when the leaf area index (LAI: predicted by the CLM-CN) is below a threshold, the soil moisture is sufficiently dry and the winds are strong enough. This desert dust flux is especially strong in areas with easily erodible soils. The desert dust is advected around the atmosphere (in 4 size bins) and is removed by dry and wet deposition. While the desert dust is in the atmosphere, it interacts with the short and long wave radiation. When the desert dust is deposited to the oceans, it interacts with ocean biogeochemistry. The desert dust module and its impact on radiative forcing and climate is described and compared to observations for satellite-based vegetation cases in (Mahowald et al., 2006a; Yoshioka et al., 2007). In the simulations presented here, the model version differs by using predicted LAI instead of fixed LAI. To test the sensitivity to secular increases or decreases in desert dust 
sources from external factors (e.g., land-use change; biogeography), we apply a time-varying global factor to adjust the effectiveness of dust generation from each grid cell. Note that this still allows soil moisture, winds and vegetation to impact the local source strength as well. For the AEROSOL cases (described below), we also changed the threshold LAI where dust production occurs (from 0.1 to 0.3 ) and do these comparisons at the grid level instead of plant functional type, to be more consistent with the model formulation and available observations (Okin, 2008).

The desert dust influences the simulated short and long wave radiation and thus induces changes in simulated climate similar to previous model studies (conducted in a version of the CCSM climate model without an interactive carbon cycle) (Mahowald et al., 2006b; Yoshioka et al., 2007). The CCSM model version does not include indirect impacts of aerosols onto cloud properties so those effects are not included in the model simulations presented here.

Once the desert dust is deposited to the oceans, we assume that $3.5 \%$ of the dust is iron, and $2 \%$ of the iron is bioavailable for ocean biota (J. K. Moore et al., 2004, 2006). This predicted dust is then used in the model as a new source of iron, instead of the fixed seasonal cycle dust deposition previously used. For the experiments with the dust cycle coupled in, small modifications to the iron cycle in the ocean were made to incorporate the impact of sedimentary sources of iron (Moore and Braucher, 2008). Moore and Braucher (2008) added a more realistic sedimentary iron source to the model, which improved the match to dissolved iron observations. This relatively strong iron source is of similar magnitude to the source from atmospheric deposition and acts to weaken the biogeochemical sensitivity to varations in the atmospheric source.

\subsection{Model experiments}

We conduct several sets of experiments that we describe here (and are summarized in Table 1). The sets of experiments can be grouped into three types: (1) control simulations, forced with preindustrial conditions, (2) transient simulations (1870-2100), forced with time varying greenhouse gas and aerosols, where biogeochemically coupled $\mathrm{CO}_{2}$ is also coupled to the radiation, and (3) transient simulations (18702100) where the radiative $\mathrm{CO}_{2}$ stays at a constant $287 \mathrm{ppm}$ (indicated with $-\mathrm{r}$ at the end of the ensemble member). The first type of simulation for each case set gives us the preindustrial control to allow us to determine the change in the climate system, while the latter simulations are used to tell us the climate feedback onto the carbon cycle. Control simulations for the BASE case were several hundred years long to obtain conditions close to equilibrium, while control simulations for other cases were 270 years, with 50 years of spinup (transient simulations were started at year 50 of control simulations in these cases), unless otherwise specified below. Because the sets of non-BASE cases considered here were not spun up for several hundred years to come into equilibrium, we substract the control case off the transient, to remove any drift in the climate.

\subsubsection{Ensemble members (BASE1, BASE2, BASE3)}

We conduct two additional sets of ensemble members of the transient simulation presented in (Thornton et al., 2009), described in Sect. 2.1. BASE1 represents the simulations presented in (Thornton et al., 2009), while BASE2 and BASE3 represent identically forced simulations, with initial conditions starting 10 years later in the control for the atmosphere, land and ocean. This allows us to consider the impacts of natural variability onto transient carbon-climate simulations. These simulations include no time varying or prognostic aerosols aerosols, but prescribed fixed aerosols, as in the default Community Atmosphere Model (Collins et al., 2006b).

\subsubsection{Sensitivity Studies (NONEQ and TRAJ)}

We conduct two sets of sensitivity studies, (1) a nonequilibrium case (NONEQ) and (2) a case with specified atmospheric $\mathrm{CO}_{2}$ concentration trajectory instead of interactive $\mathrm{CO}_{2}$ (TRAJ). We normally integrate the carbon cycle model during spin-up until land, atmosphere and ocean carbon stocks are drifting less than $0.01 \mathrm{Pg}_{\text {year }}{ }^{-1}$ globally averaged. In the non-equilibrium set of cases (NONEQ), we consider how close to equilibrium the model needs to be in order to simulate the transient response correctly. For this set of cases, we conduct new control and transient simulations (with and without radiatively coupled carbon dioxide) covering 230 years (1870-2100) from a new perturbed initial condition where the model is not in equilibrium. This initial condition was generated with the same model, but with slightly incorrect coding; the NONEQ model configuration has global carbon drifts of $0.08 \mathrm{PgC} \mathrm{year}^{-1}$ for the land and ocean, in opposite directions, so that the total atmospheric $\mathrm{CO}_{2}$ is roughly in equilibrium. At individual land model grid cells averaged over years $26-35$, the flux imbalance was as large as $1.6 \mathrm{~kg} \mathrm{~m}^{-2}$ year $^{-1}$. We start the transient simulations 25 years after the control simulation starts. We difference all results from the control simulation, so that the drift in the control is subtracted from the trends in the transient prior to analysis.

For the second sensitivity set of cases, TRAJ, we use the globally averaged atmospheric $\mathrm{CO}_{2}$ concentration from the BASE1 simulation to drive the biogeochemistry and radiative interactions in the model. When the prognostic biogeochemically coupled carbon dioxide is used, strong lateral and vertical gradients in atmospheric $\mathrm{CO}_{2}$ can arise due to the uptake and emission of carbon dioxide over the terrestrial biosphere (e.g. Denning et al., 1995). This could impact the terrestrial biosphere due to the spatially and temporally varying carbon dioxide experienced by the plants affecting photosynthesis. 
Table 1. Model Cases.

\begin{tabular}{|c|c|c|}
\hline Case names & Case descriptions & Aerosol description \\
\hline BASE-Control & Base model preindustrial control & Prescribed aerosols \\
\hline BASE1 & Base model transient simulations & Prescribed aerosols \\
\hline BASE1-r & $\begin{array}{l}\text { Base model transient simulation, } \\
\text { with } \mathrm{CO}_{2} \text { fixed at } 287 \text { for radiation }\end{array}$ & Prescribed aerosols \\
\hline BASE2 & Base model transient simulations & Prescribed aerosols \\
\hline BASE2-r & $\begin{array}{l}\text { Base model transient simulation, } \\
\text { with } \mathrm{CO}_{2} \text { fixed at } 287 \text { for radiation }\end{array}$ & Prescribed aerosols \\
\hline BASE3 & Base model transient simulations & Prescribed aerosols \\
\hline BASE3-r & $\begin{array}{l}\text { Base model transient simulation, } \\
\text { with } \mathrm{CO}_{2} \text { fixed at } 287 \text { for radiation }\end{array}$ & Prescribed aerosols \\
\hline NONEQ-Control & $\begin{array}{l}\text { Base model preindustrial control, } \\
\text { started with initial conditions that } \\
\text { are out of balance from model }\end{array}$ & Prescribed aerosols \\
\hline NONEQ & $\begin{array}{l}\text { Base model transient simulation, } \\
\text { with out of balance initial condition }\end{array}$ & Prescribed aerosols \\
\hline NONEQ-r & $\begin{array}{l}\text { Base model transient simulation, } \\
\text { with out of balance initial condition, } \\
\text { with } \mathrm{CO}_{2} \text { fixed at } 287 \text { for radiation }\end{array}$ & Prescribed aerosols \\
\hline TRAJ-Control & $\begin{array}{l}\text { Base model, control simulation, with } \\
\text { averaged } \mathrm{CO}_{2} \text { concentration from BASE1 } \\
\text { simulation for biogeochemistry }\end{array}$ & Prescribed aerosols \\
\hline TRAJ & $\begin{array}{l}\text { Base model, transient simulation, with } \\
\text { averaged } \mathrm{CO}_{2} \text { concentration from BASE1 } \\
\text { simulation for biogeochemistry }\end{array}$ & Prescribed aerosols \\
\hline DUST-Control & Dust model, preindustrial control & $\begin{array}{l}\text { Desert dust interactive, } \\
\text { other aerosols prescribed }\end{array}$ \\
\hline DUST & Dust model, transient simulation & $\begin{array}{l}\text { Desert dust interactive, } \\
\text { other aerosols prescribed }\end{array}$ \\
\hline DUST-r & $\begin{array}{l}\text { Dust model, transient simulation, } \\
\text { with } \mathrm{CO}_{2} \text { fixed at } 287 \text { for radiation }\end{array}$ & $\begin{array}{l}\text { Desert dust interactive, } \\
\text { other aerosols prescribed }\end{array}$ \\
\hline $2 \times$ DUST & $\begin{array}{l}\text { Dust model, transient simulations, } \\
\text { with dust source effectiveness doubling } \\
\text { over the simulations }\end{array}$ & $\begin{array}{l}\text { Desert dust interactive, } \\
\text { other aerosols prescribed }\end{array}$ \\
\hline $0.5 \times$ DUST & $\begin{array}{l}\text { Dust model, transient simulations, } \\
\text { with dust source effectiveness halving } \\
\text { over the simulations }\end{array}$ & $\begin{array}{l}\text { Desert dust interactive, } \\
\text { other aerosols prescribed }\end{array}$ \\
\hline AEROSOL-Control & Aerosol model, preindustrial control & $\begin{array}{l}\text { Desert dust, sulfate aerosols } \\
\text { interactive, carbonaceous } \\
\text { aerosols vary with time }\end{array}$ \\
\hline AEROSOL & Aerosol model, transient simulation & $\begin{array}{l}\text { Desert dust, sulfate aerosols } \\
\text { interactive, carbonaceous } \\
\text { aerosols vary with time }\end{array}$ \\
\hline AEROSOL-r & $\begin{array}{l}\text { Aerosol model, transient simulation, } \\
\text { with } \mathrm{CO}_{2} \text { fixed at } 287 \text { for radiation }\end{array}$ & $\begin{array}{l}\text { Desert dust, sulfate aerosols } \\
\text { interactive, carbonaceous } \\
\text { aerosols vary with time }\end{array}$ \\
\hline
\end{tabular}


In the TRAJ cases, we use a uniform global mean $\mathrm{CO}_{2}$ distribution (which is set to the same as the calculated globally averaged value from the BASE1 simulation) to see if disallowing gradients in $\mathrm{CO}_{2}$ changes our simulations. The maximum surface $\mathrm{CO}_{2}$ concentration difference (high minus low) for the monthly average is $65 \mathrm{ppm}$, and the standard deviation is $12 \mathrm{ppm}$ in our model (BASE1), and it is this variability that is excluded from the TRAJ case. This case has relevance for the differences in protocols between different modeling groups: for example the Friedlingstein et al. (2003) only keeps one global average in their simulations, while in our model, we simulate the full 3-dimensional distribution of $\mathrm{CO}_{2}$. Finally this has relevance in the upcoming simulations for next Intergovernmental Panel on Climate Change, where all the models will be run with a $\mathrm{CO}_{2}$ trajectory and the allowed anthropogenic fluxes will be inferred (Taylor et al., 2009). Oeschlies (2009) showed that the $\mathrm{CO}_{2}$ boundary conditions used for ocean-only experiments change the resulting carbon uptake; here we explore the importance of the formulation of the boundary condition of $\mathrm{CO}_{2}$ for coupled experiments

\subsubsection{Desert dust experiments (DUST, $2 \times$ DUST, $0.5 \times$ DUST)}

We conduct several experiments where we include the impacts of prognostic and changing desert dust onto the climate and biogeochemistry of the model. The desert dust module (as described in Sect. 2.2.1) is included and coupled with the land surface for source generation, the atmosphere radiation and the ocean biogeochemistry as dust is deposited on the surface (DUST). We also conduct two simulations where we force the desert dust source strength at every point to either double or half over time $(2 \times$ DUST, $0.5 \times$ DUST $)$, because of the uncertainties in the response of desert dust to humans (discussed in Sect. 1.0). In these simulations, desert dust is the same at 1870 , but is either doubled $(2 \times$ DUST $)$ or halved $(0.5 \times$ DUST $)$ at 2100 , with a linear interpolation in time in between.

\subsubsection{Aerosol experiments (AEROSOL)}

For these experiments, we use aerosol anthropogenic forcing from the IPCC A1B scenario (Meehl et al., 2006) which include: prognostic sulfate aerosols (with time varying emissions), prescribed organic and black carbon aerosol distribution (with time varying magnitude), prescribed seasalt aerosols, prescribed volcanic aerosol (with time varying magnitude) (Meehl et al., 2006). These forcings include historical estimates of emissions of sulfur compounds and variability in the magnitude of volcanic and carbonaceous aerosols over 1870-2000, and then future projections for 2000-2100. Note that there are no volcanoes past 2000 in these simulations. For these simulations, we include prog- nostic desert dust and the impact of these aerosols onto climate and biogeochemistry as well.

\subsection{Simple feedback analysis}

In order to understand the coupled-carbon-climate model simulations, we utilize and adapt a previously published, simple carbon-climate feedback analysis (Friedlingstein et al., 2003, 2006). We briefly describe this model here, and extend this model in a simple way to include the primary impacts of aerosols onto the coupled-carbon-climate system. For the fully coupled simulations (where carbon dioxide is allowed to change in the radiation subroutine, thus affecting climate), assume a simple linear relationship:

$\Delta C_{L}^{C}=\beta_{L} \Delta C_{A}^{C}+\gamma_{L} \Delta T^{C}$

$\Delta C_{O}^{C}=\beta_{O} \Delta C_{A}^{C}+\gamma_{O} \Delta T^{C}$

where $\Delta C_{L}^{C}$ and $\Delta C_{O}^{C}$ are the change in the amount of carbon with time in the global land and ocean reservoirs, respectively (in $\mathrm{PgC}$ ), in the fully coupled simulations. The terms $\beta_{L}$ and $\beta_{O}$ relate the direct changes in land and ocean carbon reservoirs, respectively, to a change in global mean atmospheric carbon dioxide $\left(\Delta C_{A}^{C}\right.$ in ppm), and $\gamma_{L}$ and $\gamma_{O}$ relate the changes in the carbon reservoirs to a change in global mean surface temperature $\left(\Delta T^{C}\right.$ in $\left.\mathrm{K}\right)$.

The impact of rising carbon dioxide concentrations onto the land and ocean are derived from the uncoupled simulations (where $\mathrm{CO}_{2}$ does not impact climate or $-\mathrm{r}$ in our case names, (Table 1):

$\Delta C_{L}^{U}=\beta_{L} \Delta C_{A}^{U}$

$\Delta C_{O}^{U}=\beta_{O} \Delta C_{A}^{U}$

The relationship between atmospheric carbon dioxide $\left(\Delta C_{A}^{C}\right.$ in ppm) and global mean surface temperature $\left(\Delta T^{C}\right.$ in $\mathrm{K})$ is the transient climate sensitivity $(\alpha)$, here defined as:

$\Delta T^{C}=\alpha \Delta C_{A}^{C}$

From this, Friedlingstein et al. (2006) show that different models have different net gain $(\mathrm{g})$ from the inclusion of the carbon cycle in the climate model:

$\Delta C_{A}^{C}=1 /(1-g) \Delta C_{A}^{U}$

where the gain $(\mathrm{g})$ is:

$g=-\alpha\left(\gamma_{L}+\gamma_{O} /\left(1+\beta_{L}+\beta_{O}\right)\right.$

This simple feedback analysis assumes that changes in carbon dioxide are the only climate forcings. It was noted in Friedlingstein et al. (2003) that other forcings could contribute to the change in temperature, but they chose to ignore these factors. Additional forcing from non- $\mathrm{CO}_{2}$ constituents (methane, nitrous oxide, chlorofluorocarbons) represent about $13 \%$ of the forcing of $\mathrm{CO}_{2}$ in the $\mathrm{Cox}$ et 
al. (2000) and Jones et al. (2003) studies, for example, which does not explain the full extent of the differences between the models considered here.

We can extend this analysis to include aerosols (and other constituents) with a few simple assumptions. Our main assumption is that aerosol impacts are due to their globally averaged forcing, not due to changes in regional climate. Then one need only include aerosols in the equation where the relationship between atmospheric carbon dioxide and surface temperature is derived (5), and modify this equation to include the impacts of aerosols based on the change in global mean aerosol optical depth $(\triangle \mathrm{AOD})$

$$
\Delta T^{C}=\alpha\left(\Delta C_{A}^{C}+\varepsilon \quad \Delta \mathrm{AOD}\right)
$$

Where $\varepsilon$ relates the climate forcing from aerosols to the climate forcing from carbon dioxide (with units of pppm $\mathrm{CO}_{2} \mathrm{AOD}^{-1}$ ). It has been shown that for many forcings, knowing just the top of atmosphere radiative forcing is sufficient to understand the climate forcing (Hansen et al., 2005). We can convert the aerosol optical depth to an equivalent carbon dioxide forcing based on the model averages presented in the last IPCC assessment report (Forster et al., 2007), where a $180 \mathrm{ppm}$ change in $\mathrm{CO}_{2}$ is estimated to represent a $1.66 \mathrm{~W} \mathrm{~m}^{-2}$ forcing, while a change in AOD from anthropogenic aerosols of 0.05 represents a radiative forcing of $-0.5 \mathrm{~W} \mathrm{~m}^{-2}$. Therefore $\varepsilon$ has a value of about $1653 \mathrm{ppm} / \mathrm{AOD}$. Aerosols are quite heterogeneous in their optical properties (and some can warm and some cool), so here we assume that our model simulations are using a similar mix of aerosols as was used in the IPCC simulations. We will evaluate this simple methodology in Sect. 3.1.

We also analyze the Hadley Center model (HADCM3LC) (Jones et al., 2003) because they also have presented results with and without aerosols. For their simulations, we assume sulfate aerosols have a radiative forcing of $-0.9 \mathrm{~W} / \mathrm{m}^{2}$, because this is the sum of the included direct and indirect effects (Johns et al., 2003). In addition, we add in the radiative forcing of changes in tropospheric ozone, as those change in their simulations. We also adjust their climate sensitivity parameter $(\alpha)$ to account for the inclusion of non- $\mathrm{CO}_{2}$ greenhouse gases (methane, nitrous oxide, $\mathrm{CFCs}$ ), so that $\alpha$ more accurately represents the response to $\mathrm{CO}_{2}$, resulting in a $13 \%$ decrease in their climate sensitivity (as non- $\mathrm{CO}_{2}$ gases represent $13 \%$ of the radiative forcing). For this analysis, we do not have information about the radiative forcing in their model, which can vary (Forster et al., 2007), therefore our analysis will have uncertainties; but we think that this type of ball-park analysis can provide insight into the importance of aerosols in coupled-carbon-climate simulations.

(Cadule et al., 2009) develop a different approach to including multiple forcings in the simple model, pointing out that the radiative forcing from $\mathrm{CO}_{2}$ should be a non-linear relationship to $\mathrm{CO}_{2}$, instead of the linear one assumed here and in Friedlingstein et al. $(2003,2006)$. Because of this nonlinearity, the simple formulas given here are not valid, and they prefer an approach based on the gain $\left(\mathrm{g}_{T}\right)$ of a system defined as:

$g_{T}(\mathrm{AER})=\left(\Delta T(\mathrm{AER})-\Delta T^{C}\right) / \Delta T^{C}$

They assume that the gain will be similar for different models for the addition of similar processes (e.g. anthropogenic aerosols or other greenhouse gases). We will contrast the implications of this formulation (9) versus Eq. (8). Our formula (8) is similar to their fomula (6).

\section{Results}

The coupled-climate-carbon model used for this study has been previously compared to observations and evaluated (Thornton et al., 2009), and its components compared to observations and evaluated as well (Thornton et al., 2007; Doney et al., 2009a, b; Randerson et al., 2009). Generally speaking, the terrestrial carbon and ocean carbon models match available observations. However, the net uptake of anthropogenic carbon by both the land and ocean together are slightly lower than observations (Thornton et al., 2009). The only new portion of this model to be evaluated is the coupling with the dust model. Comparisons to available observations for the dust cycle as coupled in this model suggest a good simulation of annual mean desert dust concentrations and deposition rates, which span over 4 orders of magnitude variation spatially (Appendix A).

\subsection{Global averaged response}

First we consider the globally averaged surface temperature, precipitation and carbon response of the coupled-carbonclimate model to the sensitivity studies and aerosols included in the different sets of cases (Fig. 1). The model trajectory in atmospheric $\mathrm{CO}_{2}$ is largely insensitive to the cases simulated (as long as $\mathrm{CO}_{2}$ is radiatively active) (Fig. 1a). There is a larger response to inclusion of aerosols in the surface temperature, since anthropogenic aerosols tend to cool the surface (Fig. 1b). The modeled $\mathrm{CO}_{2}$ trajectory differs from the response from the Hadley Center model (HADCM3LC) (Jones et al., 2003), in which inclusion of aerosols leads to large differences in projected carbon dioxide. We postulate that this is largely due to the different climate feedbacks onto the carbon cycle, as we will discuss later.

Next we consider the feedback of the climate change onto the carbon cycle (Fig. 2). Note that the set of simulations published previously (BASE1 in Thornton et al. (2009) have the largest negative climate feedback of the ensemble members. One of the ensemble members (BASE3) has a net change at 2100 of only $-2 \mathrm{ppm}$. We interpret the range of the three ensemble members as a measure of the uncertainty due to interannual variability and initial conditions. Inclusion of dust, aerosols, or the non-equilibrated initial condition does 

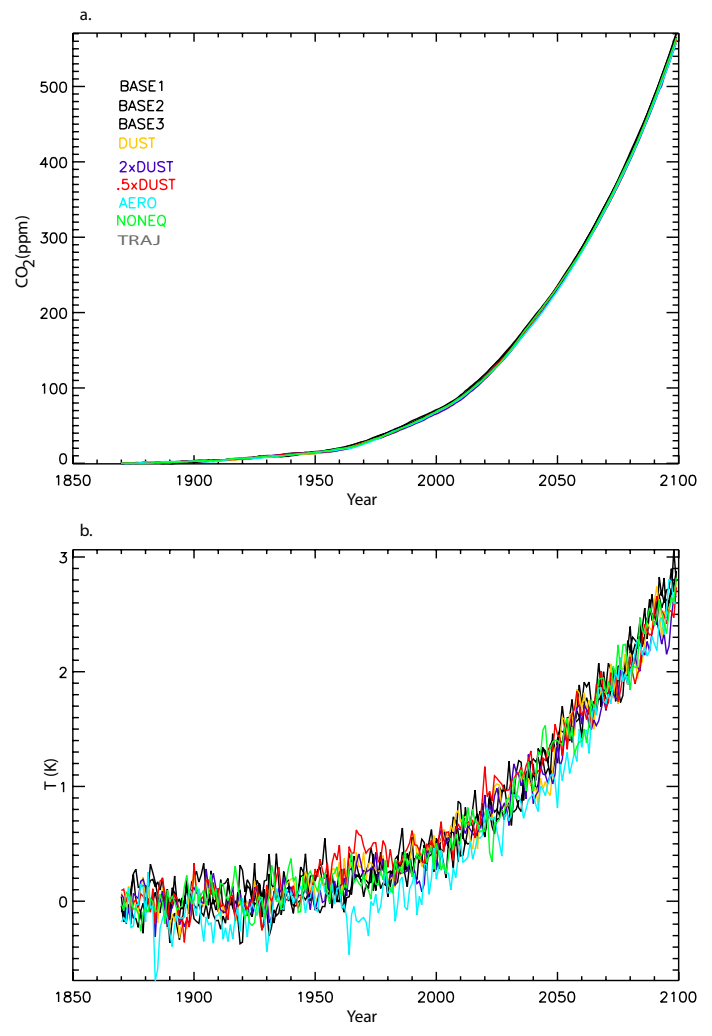

Fig. 1. Globally averaged change in $\mathrm{CO}_{2}$ concentration (ppm) (a) and surface temperature $(\mathrm{K})$ from the preindustrial control for the cases with $\mathrm{CO}_{2}$ fully interactive from Table 1 from 1870 to 2100 . All globally averaged $\mathrm{CO}_{2}$ concentrations are averaged over the whole atmosphere in this paper.

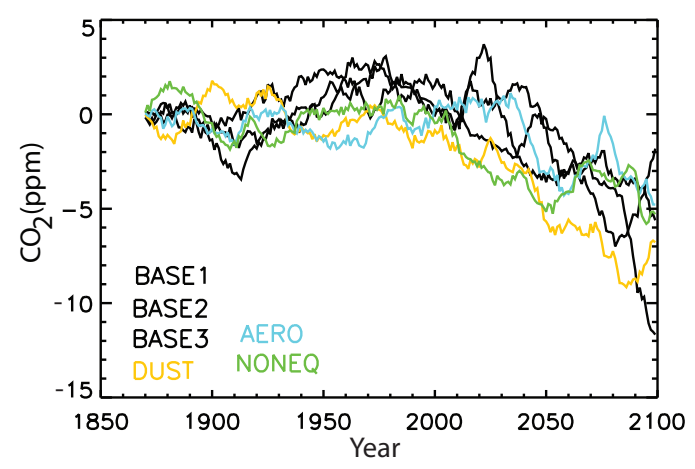

Fig. 2. Globally averaged change in $\mathrm{CO}_{2}$ (ppm) from including climate impacts from $\mathrm{CO}_{2}$ in the coupled-carbon-climate model for each case in Table 1 for 1870-2100. This is calculated using the case where $\mathrm{CO}_{2}$ is fully interactive minus the case where $\mathrm{CO}_{2}$ is set to $287 \mathrm{ppm}$ for radiation, e.g. no climate change from $\mathrm{CO}_{2}$ directly (CASE minus CASE-r).

not result in a statistically significant change of climate feedback onto the carbon cycle, which is negative in all sets of cases (Fig. 2).
While the sensitivity studies and the inclusion of dust or other aerosols into these simulations does not impact the 0th order carbon dioxide concentrations (Fig. 1), it does result in a statistically significant change in the global averaged carbon flux. The change in desert dust aerosol optical depth and total aerosol optical depth (Fig. 3a, b) show the desert is relatively stable in most cases (DUST or AEROSOL), only changing more than $20 \%$ when forced by the source strength doubling $(2 \times$ DUST $)$ or halving over time $(0.5 \times$ DUST $)$. The anthropogenic aerosols maximize in 2030, and thereafter go down in this scenario (Fig. 3b). Volcanic eruptions can clearly be seen as spikes in the aerosol optical depth (Fig. 3b).

The change in the evolution of carbon reservoirs due to including additional processes tends to lower the $\mathrm{CO}_{2}$ in the atmosphere by between 2 to $10 \mathrm{ppm}$ at 2100 for the different cases (Fig. 3c). The largest changes in $\mathrm{CO}_{2}$ concentration are seen in simulations in which the dust source is forced to double, and when aerosols are included in the simulations. The latter case cools the atmosphere (Fig. 3f). For the case where desert dust doubles over the time period of the simulation, the ocean tends to drawdown more $\mathrm{CO}_{2}$ (Fig. 3e), but the land releases slightly more $\mathrm{CO}_{2}$ (Fig. 3d). For the case of anthropogenic aerosols, the land and ocean both respond roughly equally to take up slightly more $\mathrm{CO}_{2}$.

Physical climate changes modify the ocean and land biogeochemistry through changes in winds (oceans) and precipitation (land and oceans), for example. In addition, the ocean model allows incoming dust to influence ocean biogeochemistry through iron in two ways: by relieving iron limitation and by enhancing nitrogen fixation (J. K. Moore et al., 2006). The oceans respond most strongly to the changes in desert dust, which increases relative to preindustrial nitrogen fixation rates by $14 \mathrm{TgN}$ year $^{-1}$ when dust doubles (Fig. 4a), and decreases by $8 \mathrm{TgN}_{\mathrm{Near}}{ }^{-1}$ when dust halves. Denitrification tends to decrease in the future due to climate change (Fig. 4a), and the net balance of reactive ocean nitrogen reflects a combination of the trends in denitrification and nitrogen fixation. Globally integrated marine biological productivity tends to go down in the future (similar to Steinacher et al., 2010), and goes down slightly more in cases with interactive aerosols, (Fig. 4b) although neither sinking particulate organic carbon (POC) or $\mathrm{CaCO}_{3}$ fluxes change more than $-0.5 \mathrm{PgC}_{\mathrm{e} e a r^{-1}}$. The reason for these changes has to do with regional budgets, and will be discussed in more detail in Sect. 3.6.

In the BASE cases, N fixation changes from 20802099 relative to preindustrial varies between 0.39 and $0.55 \mathrm{TgN} \mathrm{yr}^{-1}$ for the ensemble members, while including interactive dust and interactive aerosols forces changes in $\mathrm{N}$ fixation of 1.22 and $3.0 \mathrm{Tg} \mathrm{yr}^{-1}$, respectively. Even greater changes are observed if dust doubles or halves over the simulation time (16.6 and $-7.5 \mathrm{Tg} \mathrm{yr}^{-1}$, respectively). For productivity, the ensemble members show changes between -0.38 and $0.63 \mathrm{PgC}_{\text {year }}{ }^{-1}$ (2080-2099 minus 

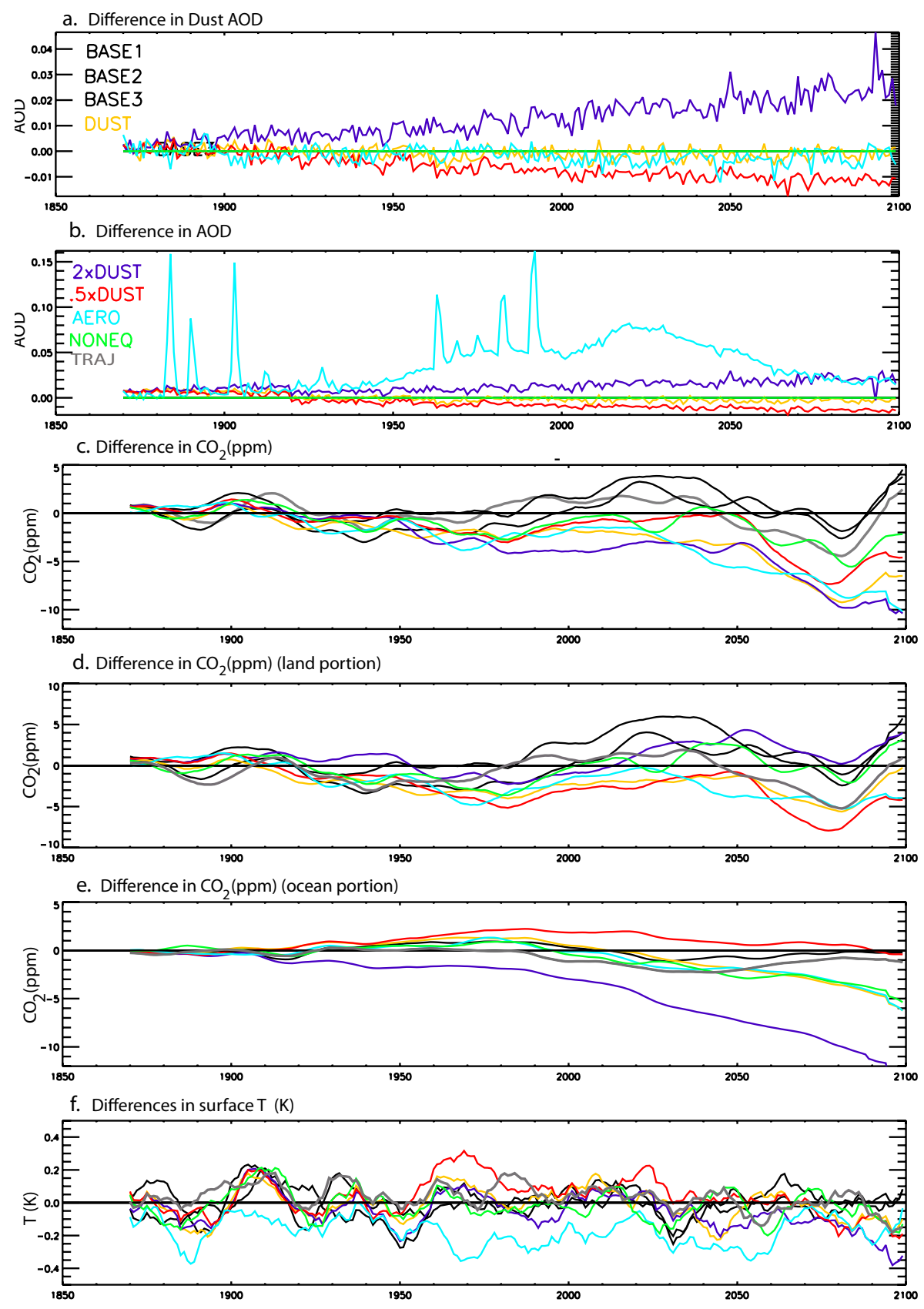

Fig. 3. Globally averaged time series for each case for the difference between each case and BASE1 for (a) dust aerosol optical depth, (b) total aerosol optical depth, (c) $\mathrm{CO}_{2}$ concentration (ppm) (the sum of $\mathbf{d}$ and $\mathbf{e}$ ), (d) $\mathrm{CO}_{2}$ concentration contribution from land (ppm), (e) $\mathrm{CO}_{2}$ concentration contribution from ocean ( $\mathrm{ppm})$ and (f) surface temperature $(\mathrm{K})$.

preindustrial), while including interactive dust and aerosols changes productivity by -0.77 and $-0.93 \mathrm{PgC}_{\text {year }}{ }^{-1}$, respectively. Allowing dust to double or half causes the changes in productivity to be -0.91 and $-1.73 \mathrm{PgC} \mathrm{year}^{-1}$. Thus, for nitrogen fixation and productivity changes, including prognostic aerosols (especially dust) causes changes which are in magnitude equal or larger than the responses from increasing $\mathrm{CO}_{2}$ in this model. Note that our model does not include changes in ocean biogeochemistry which directly result from the chemical changes in the ocean due to the additional $\mathrm{CO}_{2}$ which could be large (Hutchins et al., 2009), but only the indirect impact of $\mathrm{CO}_{2}$ onto biogeochemistry through changes in the physical climate. These changes are due to regional budget changes discussed below in Sect. 3.6. Note, however, that these simulations do not include potential significant direct effects of rising aqueous 


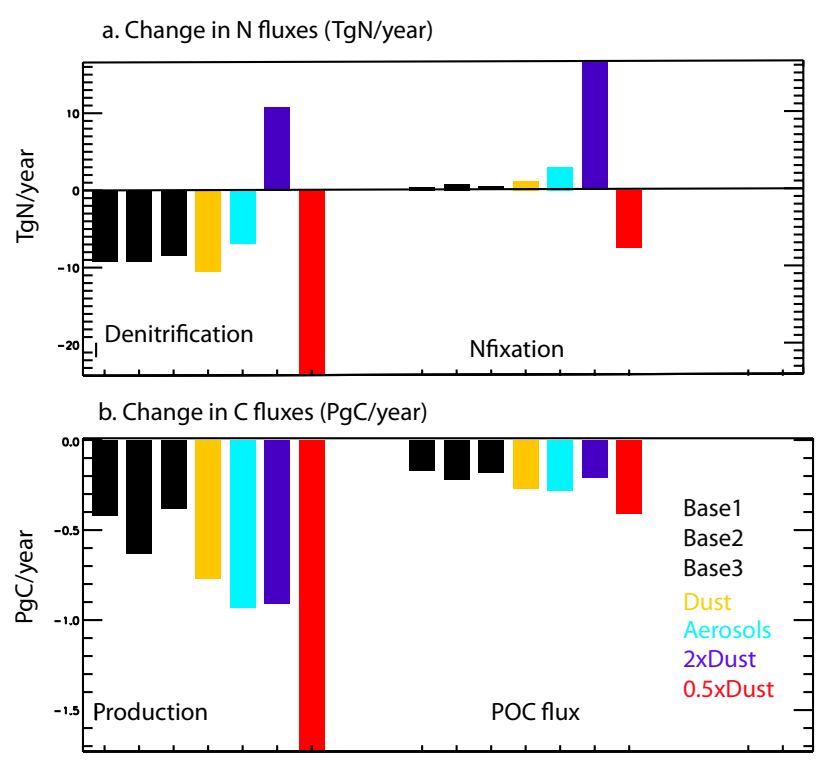

Fig. 4. Change in ocean fluxes for (a) the Nitrogen cycle ( $\mathrm{Tg}$ $\mathrm{N}$ year $\left.{ }^{-1}\right)$ and the $(\mathbf{b})$ Carbon cycle $\left(\mathrm{Pg} \mathrm{C}_{\text {year }}{ }^{-1}\right)$. For the nitrogen cycle we consider denitrification and nitrogen fixation. For the carbon cycle, we consider productivity, and particulate organic carbon flux at $103 \mathrm{~m}$. These represent changes between 2080-2099 and the preindustrial control for each case.

$\mathrm{CO}_{2}$ concentrations on primary productivity or nitrogen fixation (Doney et al., 2009c). Even with higher nitrogen fixation rates in the model, the productivity predicted by the ocean model is reduced in all the cases, but especially with interactive aerosols, by between -0.5 to $-1.5 \mathrm{PgC}_{\text {year }}{ }^{-1}$ (Fig. $4 \mathrm{~b}$ ). The temporal evolution of the nitrogen fixation and productivity illustrate that these increase at first with higher dust deposition, but then productivity starts going down (Fig. 5). The causes of these changes are discussed in more detail in Sect. 3.6.

Similar results to those shown here were seen in oceanonly results using the same biogeochemistry model (Krishnamurty et al., 2009). The changes in productivity seen here are slightly larger than those seen in Tagliabue et al. (2008) although both models contain large continental shelf sources of iron. Tagliabue et al. (2008) assume a lower solubility for the Fe in aerosols ( $0.5 \%$ compared with our $2 \%)$ causing sedimenatry inputs to dominate the iron budget. Tagliabue et al. (2008) show similar changes in the $\mathrm{N}$ cycle to those seen here. The asymmetric response of productivity to changes in dust deposition noted in Parekh et al. (2006) are seen to some extent in the productivity responses (much larger reduction in the case where dust goes down), but are not seen in the carbon fluxes (Fig. 4). That model did not consider the large sources of iron from continental shelves (Elrod et al., 2004; Lam and Bishop, 2008).

\subsection{Carbon-climate-aerosol feedbacks}

We quantify climate-carbon cycle interactions in the CCSM3 simulations by applying the feedback analysis described in Sect. 2.3 to the climate coupled (CASE) and radiatively uncoupled cases (CASE-r). We calculate the coefficients of the climate sensitivity $(\alpha)$, land response to carbon dioxide $\left(\beta_{L}\right)$ and climate $\left(\gamma_{L}\right)$, and the ocean response to carbon dioxide $\left(\beta_{O}\right)$ and climate $\left(\gamma_{O}\right)$, and the gain $g$ in the coupled-carbonclimate system (Friedlingstein et al., 2006) for each of our set of cases (Fig. 6; definition of these terms in Sect. 2.3). The model simulates a small negative feedback of climate onto the carbon cycle, and the gain in our model is very small (Fig. 6). Notice that the meaning of some of the terms of the original feedback analysis from Friedlingstein et al. (2006) is less well defined when there are additional climate forcings from aerosols. As discussed in Sect. 2.3, we can include the impact of the globally averaged cooling from aerosols in this analysis, and obtain new estimates of the carbon sensitivity $(\alpha)$ for the AEROSOL case, which better match the BASE cases, although this does not work as well for the DUST case. Plattner et al. (2008) shows that the sensitivity between carbon and climate also changes under different future emission scenarios, which is not considered here.

The largest shifts in the coefficients in the prognostic aerosol cases (DUST, AEROSOL) come in the land response to climate, which becomes more positive in the simulations with time evolving dust aerosols (Fig. 6d). This is consistent with the regional climate change that is forced by the aerosols and the feedback onto the carbon cycle (e.g. Penner et al., 2001; Jones et al., 2001; Yoshioka et al., 2007; Sects. 3.3 and 3.4). Sulfate aerosols tend to cool the climate, especially the Northern Hemisphere (Penner et al., 2001), while, desert dust aerosols tend to cool the atmosphere, and shift the precipitation away from dusty regions (Yoshioka et al., 2007).

Next we consider how to explain the large change in $\mathrm{CO}_{2}$ seen in the HADCM3LC model when aerosols are introduced (Jones et al., 2003), versus the small change in $\mathrm{CO}_{2}$ we see in these simulations (AEROSOL). As noted in the methodology Sect. 2.3 and Friedlingstein et al. (2003), the HADCM3LC simulations included other greenhouse gases, and so their alpha parameter is larger because of this inclusion. We can exclude the warming from these gases (similar to how we include the aerosols; Sect. 2.3), and we obtain a climate sensitivity for the HADCM3LC which is $13 \%$ lower than if we ignore the non- $\mathrm{CO}_{2}$ greenhouse gases $(0.0057$ vs. $0.0066 \mathrm{~K} \mathrm{ppm}^{-1}$ ) (forcings are shown in Fig. 7a). The HADCM3LC included sulfate aerosols (including the indirect effect) and ozone changes in the Jones et al. (2003) study, that were not in the Cox et al. (2000) study: these represent new forcings, and we show an estimate of these radiative forcings (Fig. 7b), along with an estimate of the forcings in AEROSOL compared to BASE cases in our study. Notice that we were not able to calculate the radiative forcings for these cases, but are estimating these based on the mean 
a. N Fixation ( $\mathrm{TgN} / \mathrm{yr})$

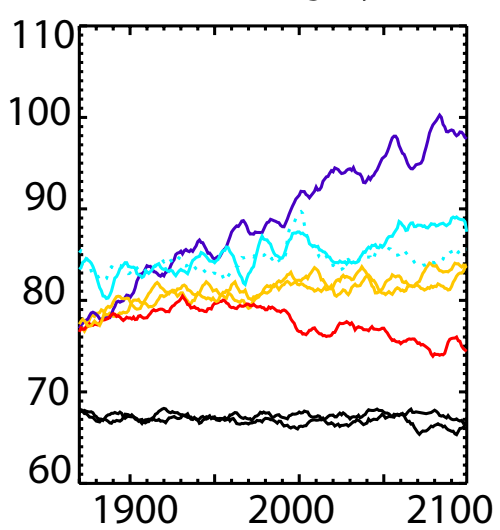

b. Production (PgC/yr)

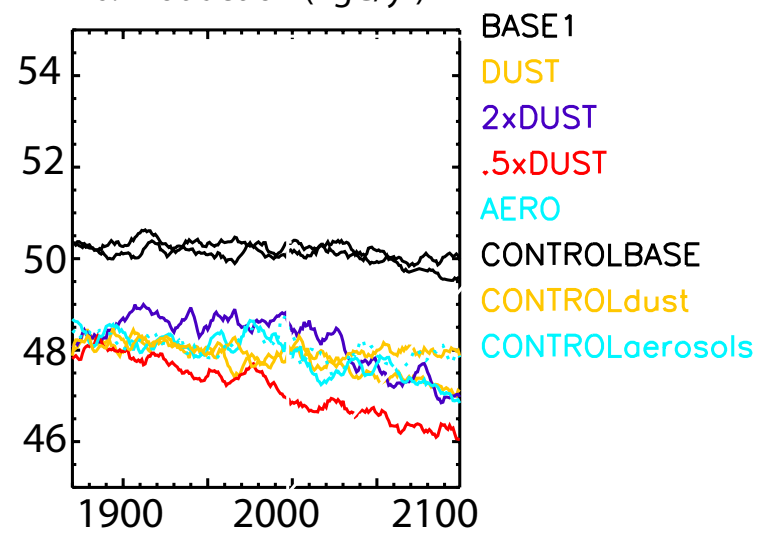

Fig. 5. Time evolution of the globally averaged (a) nitrogen fixation $\left(\mathrm{TgN}_{\text {year }}{ }^{-1}\right)$ and (b) primary production $\left(\mathrm{PgC} \mathrm{year}^{-1}\right)$.
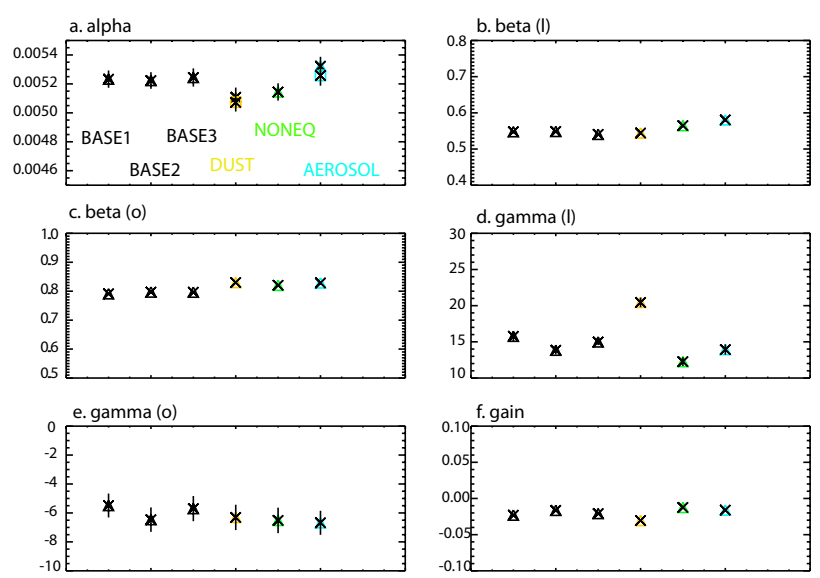

Fig. 6. Feedback parameters, alpha $\left({ }^{\circ} \mathrm{K} \mathrm{ppm} \mathrm{CO}_{2}\right)^{-1}$ (a), beta (land) $\left(\mathrm{PgC} \mathrm{ppm}^{-1} \mathrm{CO}_{2}\right)(\mathbf{b})$, beta (ocean) $\left(\mathrm{PgC} \mathrm{ppm}^{-1} \mathrm{CO}_{2}\right)(\mathbf{c})$, gamma (land) $\left(\mathrm{PgC}^{\circ} \mathrm{K}^{-1}\right)(\mathbf{d})$, gamma (ocean) $\left(\mathrm{PgC}^{\circ} \mathrm{K}^{-1}\right)(\mathbf{e})$ and gain (unitless) (e) from the Friedlingstein et al., 2006 simple model, described in Sect. 2.3, for the 3 ensemble members, and the cases of dust, non-equilibrium and aerosols.

reported for the models included in Forster et al. (2007). For this analysis we are assuming that the impact on globally averaged temperature of the radiative forcing is similar for all constituents, which appears to hold true for these constituents (Hansen et al., 2005). Using these changes in global forcings and the simple model presented in Sect. 2.3, we can split the aerosol response of the coupled-carbon-climate model into two parts: one driven by the globally averaged top of atmosphere aerosol forcing (usually cooling), and one resulting from regional climate shifts in precipitation, temperature and insolation (including shifts in diffuse and direct radiation). The first, globally averaged response, is estimated by the simple feedback analysis from Sect. 2.3 (Fig. 7c). Our model has much smaller response $(<10 \mathrm{ppm}$ versus $40 \mathrm{ppm})$ to aerosols than the model of Jones et al. (2003) (Fig. 7c), and this strong difference in response is estimated by the simple feedback analysis (Fig. 7c). This suggests that much of the difference in response to aerosols between HADCM3LC and our study lies predominately in the global climate feedback onto the carbon cycle, which is large in the case of the HADCM3LC model (e.g. Cox et al., 2001; Friedlingstein et al., 2006) and small (and slightly negative) in our case (Thornton et al., 2009, or here Fig. 6). In addition, because the HADCM3LC simulation includes the indirect effect of aerosols, they also have a larger forcing, although this is partially offset by the warming from additional tropospheric ozone (Fig. 7b). While aerosols also drive a regional climate response (described in more detail for this model in Sect. 3.3) and change diffuse radiation (e.g. Mercado et al., 2009), the globally averaged change in temperature from the aerosols can explain much of the signal in these two studies (Fig. 7c). Notice that the simple model does not accurately predict all of the changes in $\mathrm{CO}_{2}$ seen in the fully coupled models (Fig. 7c) and clearly regional climate change and changes in diffuse and direct insolation are playing a role at the 10-30 ppm level according to this analysis (Fig. 7c), as well as modifying the timing of the shifts in carbon dioxide.

Because of the non-linear theoretical relationship between carbon dioxide concentrations and atmospheric forcing, Cadule et al. (2009) argue that the simple model of Friedlingstein et al. (2006) should be replaced by a gain for temperature separate than the gain for $\mathrm{CO}_{2}$. They argue that this gain should be similar for multiple models. Using their methodology the gain (Eq. 9 in Sect. 2) in our system for adding interactive carbon, dust and anthropogenic aerosols are -1 , -4 and $-5 \%$, respectively. The addition of anthropogenic aerosols has a gain similar to the values quoted in Cadule et al. (2009; these are derived in a submitted article), but the coupling of carbon has the opposite sign, consistent with the small negative feedback seen in the impact of climate onto the carbon cycle in these simulations. 


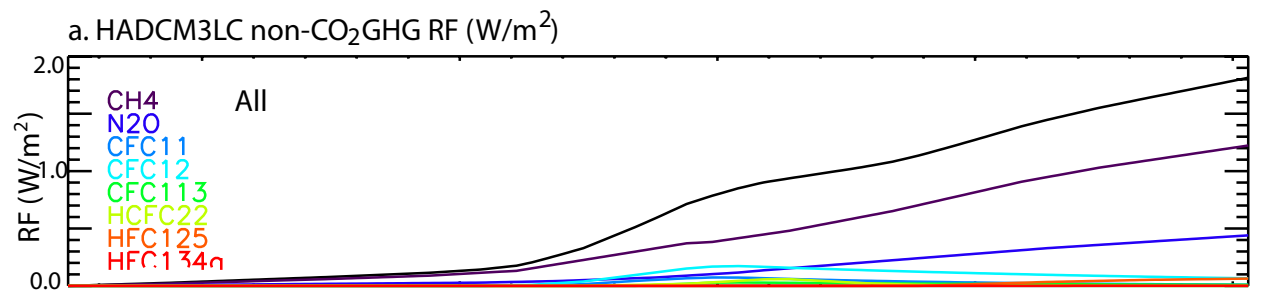

b. Differences in forcings $(\mathrm{W} / \mathrm{m})$ (AEROSOL-BASE)

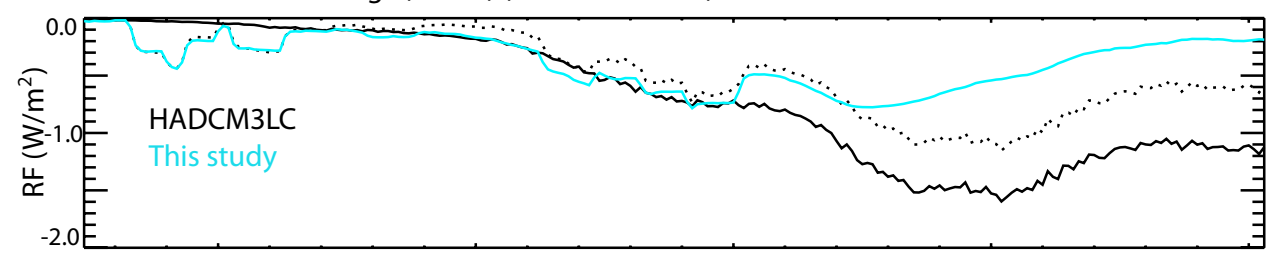

c. Differences in $\mathrm{CO}_{2}$ (ppm) (AEROSOL-BASE)

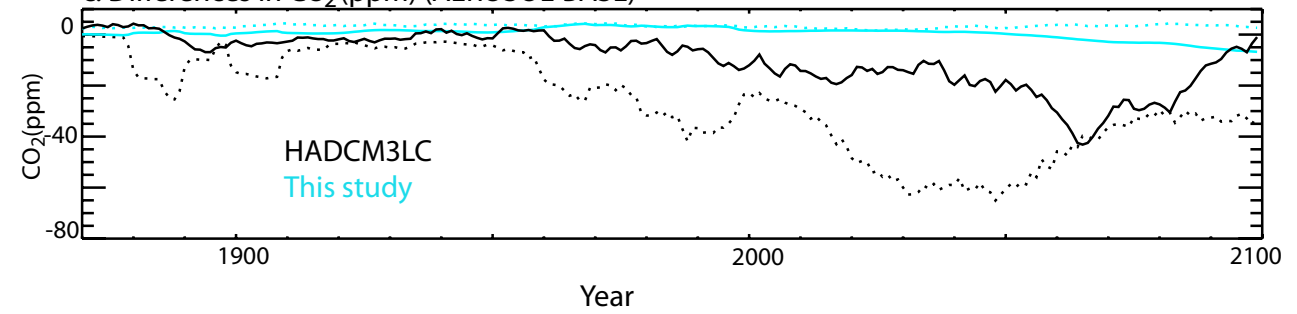

Fig. 7. Radiative forcing from non- $\mathrm{CO}_{2}$ greenhouse gases for the $\mathrm{HADCM} 3 \mathrm{LC}\left(\mathrm{W} \mathrm{m}^{-2}\right)$ from all constituents (black) and from methane, nitrous oxide, CFC11, CFC12, CFC113, HCFC22, HCFC125, HCFC134a $\left(\mathrm{W} \mathrm{m}^{-2}\right)$ (a). Differences in radiative forcings from the AEROSOLBASE case for this study (cyan) and for the HADCM3LC study (Jones et al., 2003 minus Cox et al., 2000) (b). The black solid line represents estimates for sulfate aerosols (direct and indirect), while the dotted black line includes the impact of troposphere ozone changes for the HADCM3LC. Carbon dioxide difference (ppm) between 1870 and 2100 for coupled-carbon-climate models with and without aerosols for the simulations here (cyan) and the HADCM3LC simulations (Jones et al., 2003 minus Cox et al., 2000) (c). Solid lines are 3-d model results, dotted lines are estimates from the simple feedback model described in Sect. 2.3 including aerosol globally averaged cooling.

Note that as Cadule et al. (2009) point out, basic physics suggests a log relationship between $\mathrm{CO}_{2}$ concentration and radiative forcing, implying the same relationship with change in temperature. However, most models actually have a linear relationship between $\mathrm{CO}_{2}$ concentration and temperature (e.g. Fig. 2a in Friedlingstein et al., 2006; Fig. 1c in Cadule et al., 2009), which is similar in our model. The correlation coefficient squared is 0.97 and 0.74 when $\mathrm{CO}_{2}$ and $\log$ $\mathrm{CO}_{2}$, respectively, are correlated with temperature (Fig. A6). Thus for many models, a simple linear relationship matches the model performance better than the log relationship suggested by theory. This suggests that the approach used here to deduce the impact of aerosols and green house gases on coupled-carbon-climate simulations may work better than the approach suggested by Cadule et al. (2009).

\subsection{Spatial response at the surface}

The spatial pattern of changes in surface temperature (20802099 relative to preindustrial) is dominated by the response to increases in $\mathrm{CO}_{2}$ (Fig. 8). The high latitude region experiences the largest predicted response of any region, as ex- pected. Inclusion of aerosols results in a statistically significant change in regional surface temperatures (Fig. 8b, c and d). There are regionally significant changes in predictions of the surface temperature for the sensitivity studies (Fig. 8e, f); for all results, only results that are significant above the $95 \%$ are shown using two sided significance tests and discussed.

The response of the fully coupled system in precipitation is consistent with the temperature (Fig. 9): the strongest responses come from the $\mathrm{CO}_{2}$ changes (Fig. 9a) with statistically significant changes from aerosols (Fig. 9b, c) as well as from the sensitivity studies (Fig. 9e, f).

How these physical climate responses are seen in the carbon fluxes at 2080-2099 is shown next. The response of the coupled-carbon-climate model to anthropogenic emissions shows an uptake of carbon in the tropical land with some reduction in carbon fluxes in high latitudes over land (Fig. 10a: a positive value means a larger flux into the atmosphere during 2080-2099 than the preindustrial). The maximum changes over land are larger than the changes over ocean, but the ocean serves as a large sink of carbon over this period. Adding in the desert dust aerosols and the 

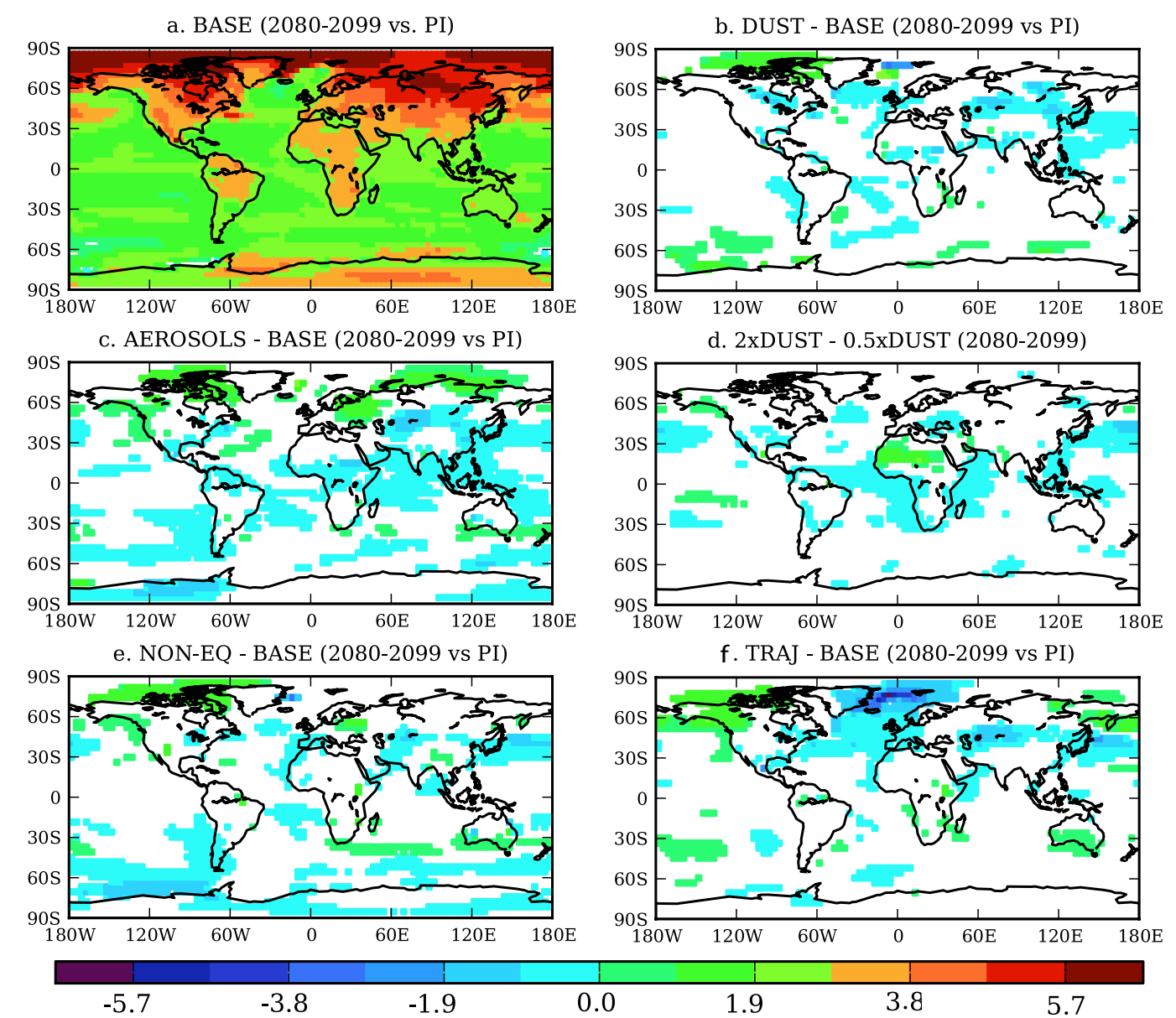

Fig. 8. Surface temperature (K) differences for 2080-2099 relative to the preindustrial control for each case: (a) mean change for 3 ensemble BASE case members, (b) differences from base case differences for interactive dust (DUST), (c) differences from BASE case for interactive aerosols (AEROSOL), (d) difference between 2xDUST and 0.5DUST cases, (e) differences from BASE case for case of NONEQ, and (f) differences from BASE for case of TRAJ. Only changes significant at the $95 \%$ level are shown in color. Notice that cases b, c, e and $\mathrm{f}$ are differences from the 3 BASE case differences from preindustrial (for example: (DUST2080-2099 minus DUST-control) minus (BASE20802099 minus BASE-control)).

anthropogenic aerosol evolution changes the details of these fluxes, but not the overall picture (Fig. 10b, c). A comparison of the simulations in which we double dust shows significant changes in carbon uptake over much of the ocean (similar to J. K. Moore et al., 2006), and some changes over land during the 2080-2099 period (Fig. 10d). The sensitivity studies where we use non-equilibrium initial conditions (NONEQ) or averaged $\mathrm{CO}_{2}$ concentrations (TRAJ) show small scale statistically significant differences, but no qualitative differences (Fig. 10e, f); in the Appendix we examine the impact of drifting controls when we do not remove the drift in the control. Our analysis does not include differences due to internal variability.

For anthropogenic aerosols, the strongest forcings are during the mid-21st century, not the end of the century (Fig. 3). Stronger regional impacts of aerosols onto surface temperature and $\mathrm{CO}_{2}$ flux can be seen at this time, although the response to $\mathrm{CO}_{2}$ is much larger at either mid-century or at the end of the 21st century (Appendix Figs. A3 and A4).

Overall, similar to our global averages, the large scale patterns are not changed significantly when aerosols are introduced into the coupled-climate-carbon cycle, although regional climate is changed. We consider in more detail next the response of the land and ocean to aerosols.

The sensitivity studies we conducted, starting from a nonequilibrated condition and conducting transients, as well as using a trajectory of $\mathrm{CO}_{2}$ concentrations rather than interactive $\mathrm{CO}_{2}$, show some statistically significant regional differences from the BASE cases. However, overall, there are not large feedbacks in the carbon cycle in these sensitivity studies. We do not further consider these sensitivity studies in the next sections, and focus on the aerosol interactions in the fully coupled-carbon-climate model. 

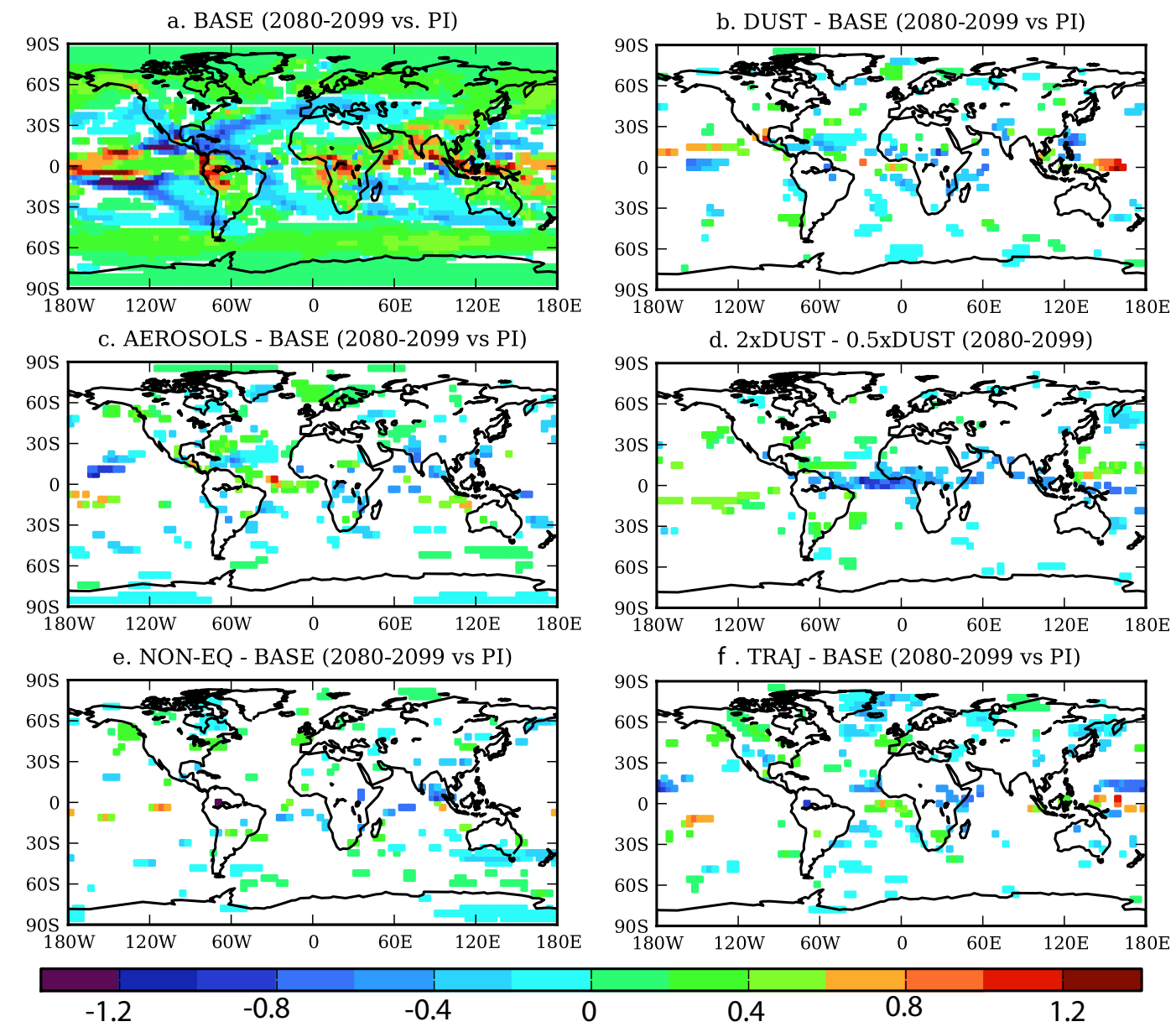

Fig. 9. Same as Fig. 8, but for precipitation $\left(\mathrm{mm} \mathrm{day}^{-1}\right)$.

\subsection{Aerosol feedbacks on land}

The total amount of carbon on land shows a large gain in carbon due to increasing $\mathrm{CO}_{2}$ (Fig. 11a) when 2080-2099 is compared to the preindustrial. Adding in aerosol interactions (11b-11d) causes regional shifts in carbon amounts, but does not change the large scale picture. The simulations with only the biogeochemistry seeing increases in $\mathrm{CO}_{2}$ (BASE-r) shows a similar change as seen in the BASE case (Fig. 11e vs. Fig. 11a), again suggesting that the climate feedbacks onto the carbon cycle are not very strong in this model. As previous analyses have indicated (Fung et al., 2005), many of the changes in the lower latitudes are correlated with changes in moisture stress (Fig. 12) related to shifts in precipitation (Fig. 9). Changes in higher latitudes do not appear to be related to statistically significant changes in mean temperature (Fig. 8), although shifts in growing season or temperature are likely to be the cause. The relationship between net carbon fluxes and soil moisture and temperature are examined in more detail in (Thornton et al., 2009).
Jones et al. (2003) showed a large response to the inclusion of aerosols into their coupled-carbon-climate cycle model, partly as a result of the loss of the precipitation onto Amazon predicted in this model under warmer conditions (Cox et al., 2000). Cooler atmosphere leads to the Amazon persisting longer, although once anthropogenic aerosols are removed, their model predicts the Amazon is lost more rapidly, as the climate warms and precipitation to this region decreases (Cox et al., 2008). The model presented here does not have this strong change in carbon response when aerosols are included (Fig. 3). In fact, this model has very little change in precipitation over the Amazon region under any conditions, in contrast to the HADCM3LC Model (Jones et al., 2003) (Fig. 13).

\subsection{Desert dust changes}

The mean simulation of desert dust is described in more detail in the Appendix. Here we discuss the changes in desert dust in the different simulations for 2080-2099 relative to the preindustrial control. Interactive dust does not change the 
a. BASE (2080-2099 vs. PI)

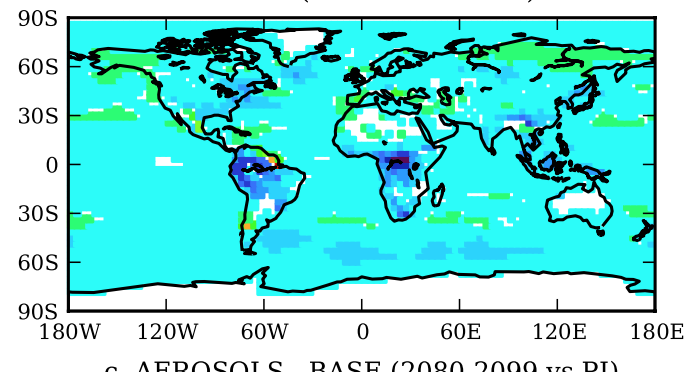

c. AEROSOLS - BASE (2080-2099 vs PI)

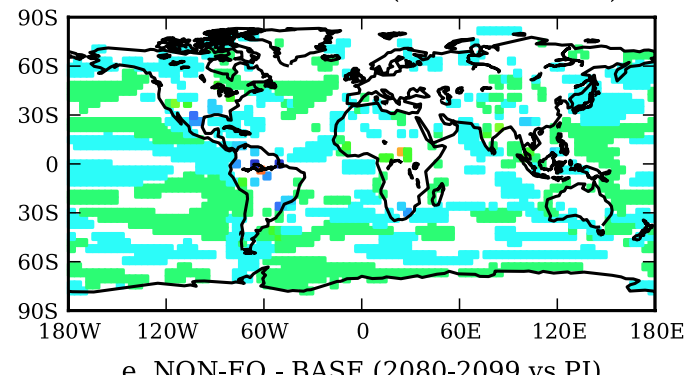

e. NON-EQ - BASE (2080-2099 vs PI)

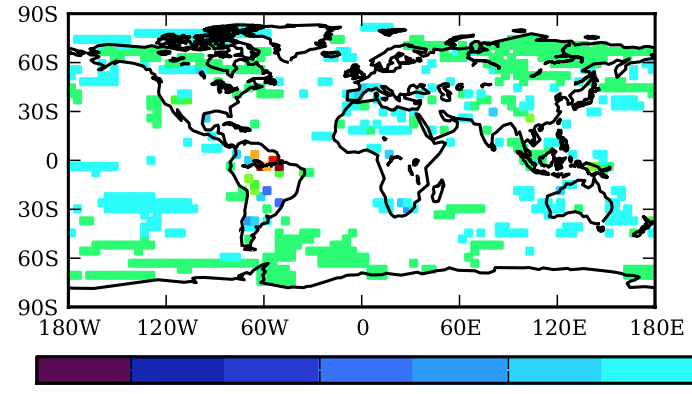

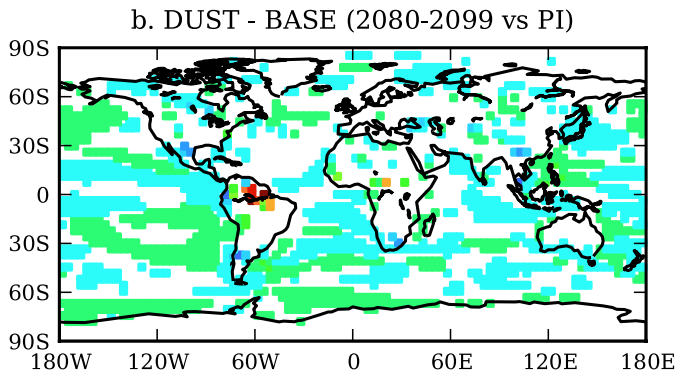

d. 2xDUST - 0.5xDUST (2080-2099)

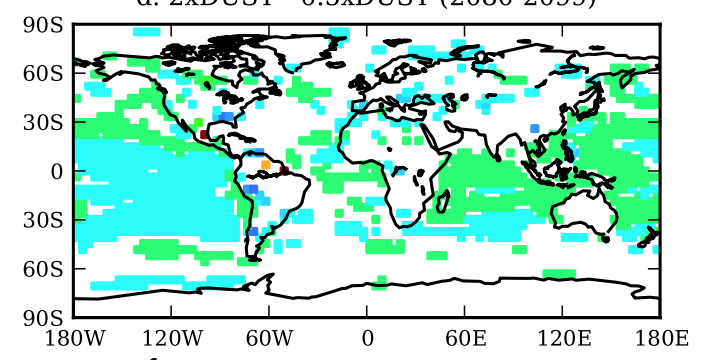

f. TRAJ - BASE (2080-2099 vs PI)

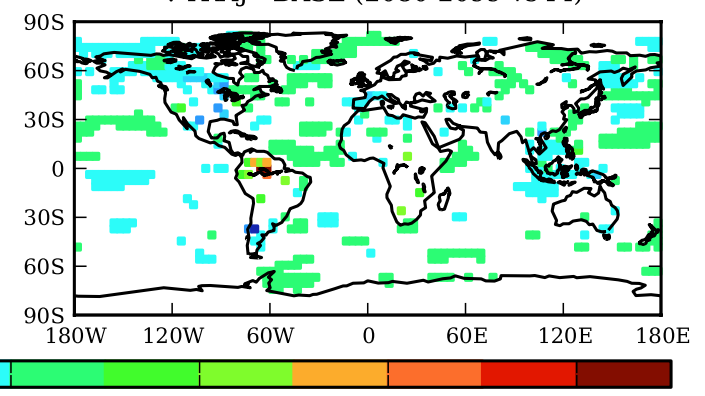

Fig. 10. Same as Fig. 8, but for $\mathrm{CO}_{2}$ fluxes $\left(\mathrm{mg} \mathrm{CO}_{2} \mathrm{~m}^{-2} \mathrm{~s}^{-1}\right)$. Carbon fluxes are positive upwards into the atmosphere. A negative value would indicate that less carbon is going into the atmosphere during 2080-2099 than during the preindustrial.

source strength for most regions more than $15 \%$, except for East Asia, South America and Australia, which are predicted to decrease by $40 \%, 75 \%$ and $20 \%$, respectively (Fig. 14d). These changes are consistent with an increase in precipitation, precipitation minus evaporation and a decrease in desert area in these regions (Fig. 14a-c). However, it should be noted that these model results do not necessarily support the theory that wet regions will get wetter and dry regions will get drier, which many models do suggest (Meehl et al., 2007); the CCSM 3 model's climate response to higher $\mathrm{CO}_{2}$ response in desert regions is different than the majority of the models (Mahowald, 2007). The desert area changes predicted here are not due to changing biogeography or land-use (which is not predicted in this model), but due to lower predicted LAIs. Notice that the model predicts a large increase in precipitation, and a corresponding decrease in desert area in the Middle East/Central Asia, but no corresponding decrease in the desert dust source strength: the winds must be important in these regions, and we did not archive high temporal data on the wind strengths to estimate this. Even in the cases where the source strength at each grid box is doubled or halved over the time of the simulation $(2 \times$ DUST and $0.5 \times$ DUST), the source strength in East Asia, South America and Australia is not responding linearly. The changes in source strength result in changes in climate from the direct radiative feedbacks included in the model. These will combine with changes in $\mathrm{CO}_{2}$ and other changes to impact surface temperature and precipitation (Figs. 8 and 9). In addition, the desert dust changes will impact downwind deposition to oceans (Fig. 14e). The impacts on downwind deposition to different ocean basins are consistent with changes to sources, with the largest changes occurring downwind of the South American and Australian sources. The East Asian sources impact the North Pacific primarily, but there are also contributions from the Middle East/Central Asian sources and the North American sources on the North Pacific, and so that deposition to the North Pacific does not change as much as the East Asian source (Fig. 14d, e, dust case). In the cases where dust source strength doubles (halves) over the simulations, most ocean basins see a doubling (halving) 
a. BASE (2080-2099 vs. PI)
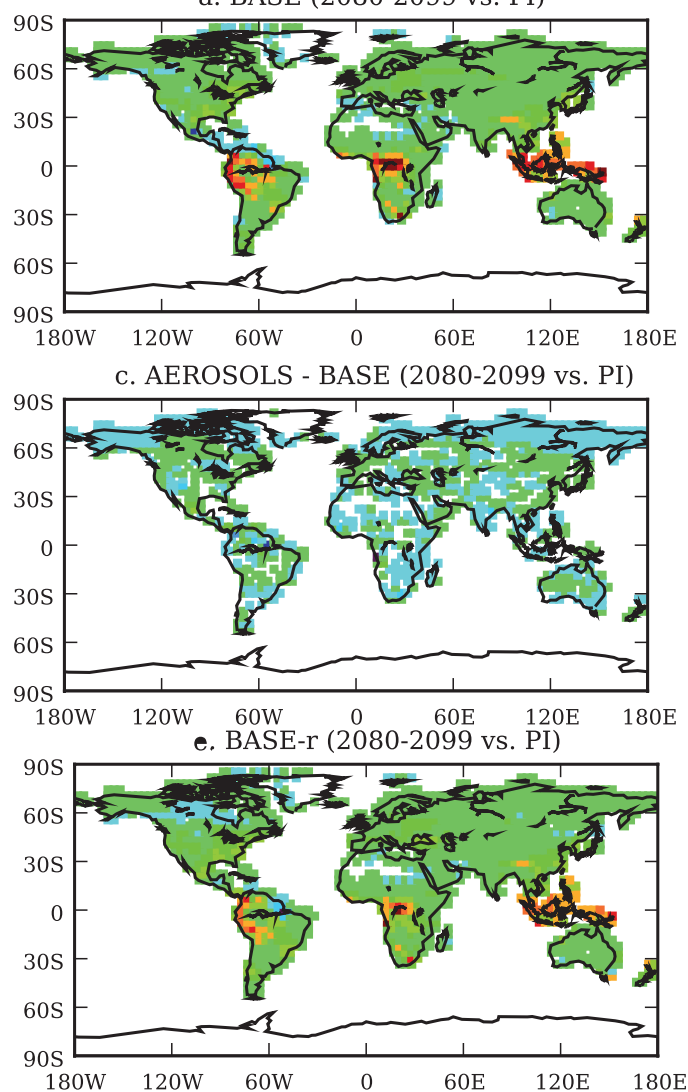

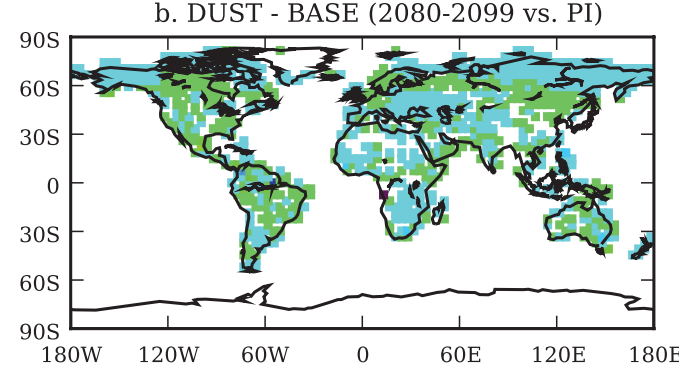

d. 2xDUST - 0.5xDUST (2080-2099)

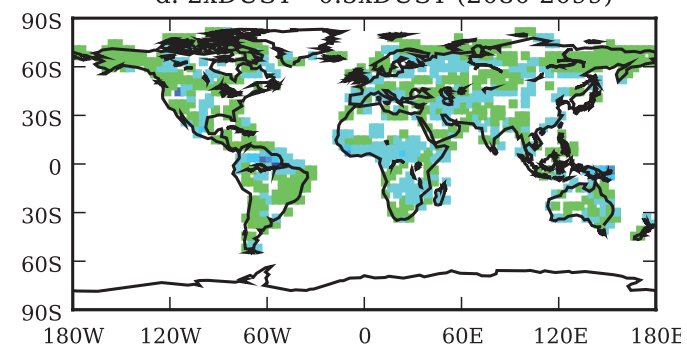

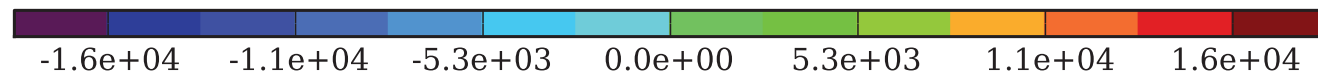

Fig. 11. Total column carbon on land $\left(\mathrm{gC} \mathrm{m}^{-2}\right)$ for 2080-2099 relative to the preindustrial control for each case: (a) mean change for 3 ensemble base case members, (b) differences from base case differences for interactive dust (DUST), (c) differences from base case for interactive aerosols (AEROSOL), (d) difference between 2xDUST and 0.5DUST cases, and (e) mean change for 3 ensemble BASE-r (CO 2 does not impact climate) case members. Only changes significant at the 95\% level are shown in color. Note that panels (b), (c), (e) and (f) show differences from the 3 BASE case differences from preindustrial (for example: (DUST2080-2099 minus DUST-control) minus (BASE2080-2099 minus BASE-control)).

of the deposition. The exceptions are the Southern Ocean regions, impacted by the South American and Australian sources (Fig. 14d, e, $2 \times$ Dust and $0.5 \times$ dust cases), where significant climate change occurs (as discussed above).

\subsection{Aerosol feedbacks onto oceans}

Total chlorophyll responses to $\mathrm{CO}_{2}$ (Fig. 15a) and the inclusion of aerosols in the coupled-carbon-climate model (Fig. 15b-d) suggest that aerosols significantly perturb chlorophyll distributions (also seen in Doney et al., 2009a) (similar to what was seen in Fig. 10). Significant changes occur in some regions. We see an increase in chlorophyll at the edge of the Southern Ocean off the coast of South America when only changes in $\mathrm{CO}_{2}$ are considered (Fig. 15a). However, this increase goes away if aerosols are included (Fig. 15b, c), because of the decrease in the dust deposition due to decreases in dust sources in the Southern Hemisphere (Fig. 14). We also see a significant decrease in productivity in the North Pacific (Fig. 15), the spatial extent of which changes with different aerosol cases, but is not ameliorated with increasing dust (Fig. 15d).

The time evolution of the ocean productivity in different basins elucidates why the global productivity goes down, even with more dust (Fig. 16a). Regions with sufficient dust inputs (e.g. North Atlantic, Fig. 16b) show a decrease in productivity, which is even faster in cases with higher dust (2xDUST vs. DUST or 0.5DUST). In these regions the additional iron does not cause additional productivity, because iron is not limiting. The model predicts a trend towards slightly more $\mathrm{P}$ and $\mathrm{N}$ limitation in the North Atlantic (not shown), probably due to a reduction in the mixed layer depth (Fig. A7). The mixed layer depths change between 2100 
a. BASE (2080-2099 vs. PI)

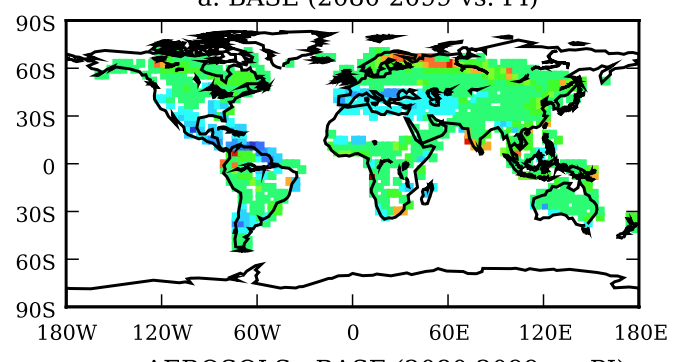

c. AEROSOLS - BASE (2080-2099 vs. PI)

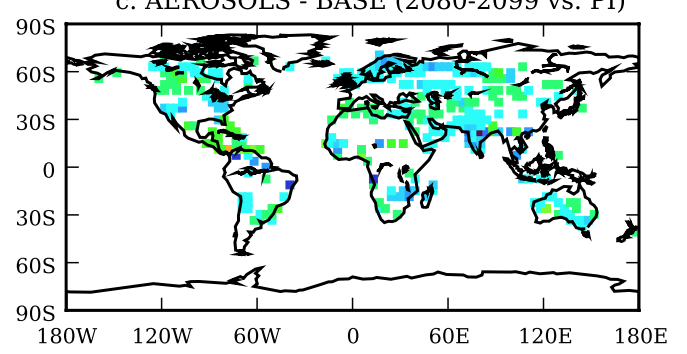

b. DUST - BASE (2080-2099 vs. PI)

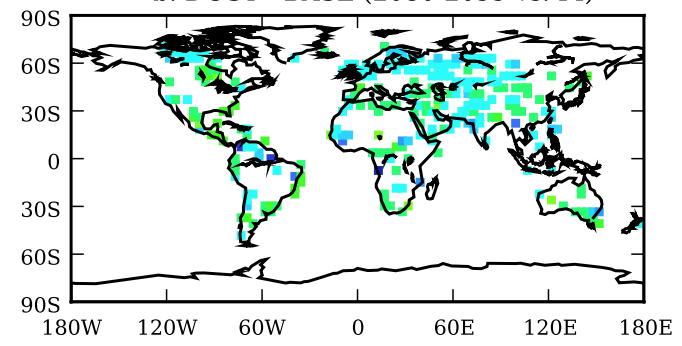

d. 2xDUST - 0.5xDUST (2080-2099)

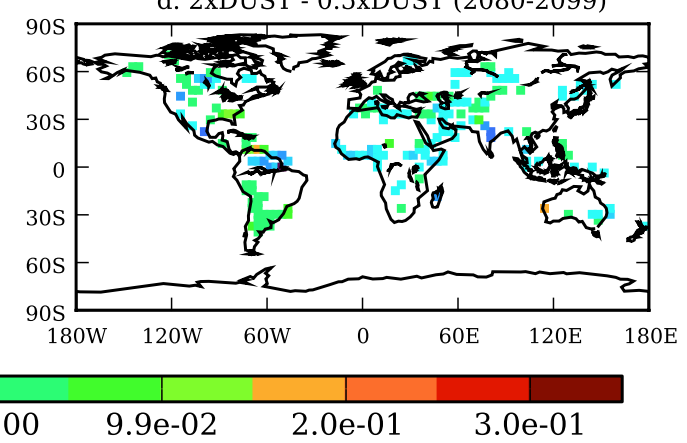

Fig. 12. Same as Fig. 11, but for Btran, a fraction indicating the level of moisture stress on photosynthesis (positive value means less moisture stress, while a negative value means more moisture stress).

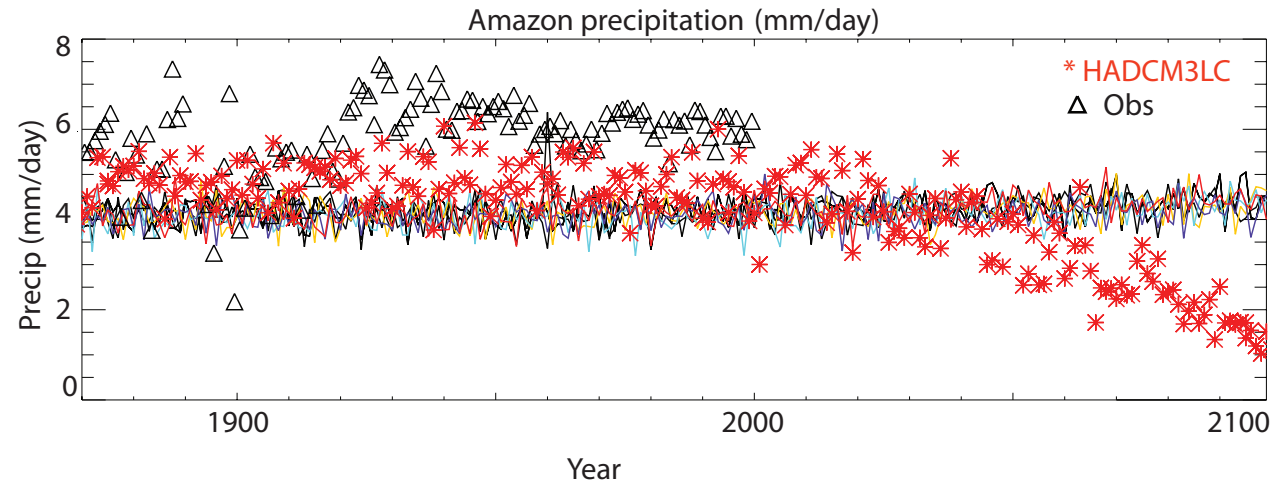

Fig. 13. Precipitation (mm day ${ }^{-1}$ ) estimates with time from 1870 to 2100 from model cases (colored lines), observations (black diamonds) and the (Jones et al., 2003) simulations using the HADCM3LC model for the Amazon region (70 W-55 W, $15 \mathrm{~S}-5 \mathrm{~N})$.

and preindustrial in the North Atlantic by $-6.3 \mathrm{~m}$ in BASE1, which increases to $-9.4 \mathrm{~m}$ when anthropogenic aerosols are introduced (AEROSOL). In the case of interactive dust (DUST) the mixed layer depth changes by $-6.8 \mathrm{~m}$ between preindustrial and 2100, while when dust doubles, this change in mixed layer depth increases to $-9.8 \mathrm{~m}(2 \times$ DUST $)$. It is not clear why increasing aerosols would cause shallower mixed layer depths: one would expect the opposite due to less surface heating since these aerosols tend to reflect and cool. A plausible explanation is that aerosols cause a decrease in surface winds during windy storms, which drive the mixed layer depths. The robustness and cause of this shallower mixed layer depth should be considered in more detail in future studies.
Many iron limited regions show an increase in productivity, especially with additional dust (e.g. $2 \times$ DUST vs. $0.5 \times$ DUST cases) (e.g. eastern S. Eq. Pacific, eastern N. Eq. Pacific, S. Pacific, S. Atlantic and S. Indian: Fig. 16d, $\mathrm{e}, \mathrm{g}$ and $\mathrm{h}$ ). Other iron-limited regions show less decline with higher dust inputs (e.g. North Pacific: Fig. 16c $2 \times$ DUST compared to $0.5 \times$ DUST). However, the Indian Ocean regions show faster decline in productivity with higher dust (Fig. 16i). This is consistent with previous studies (e.g. Krishnamurty et al., 2009; Parekh et al., 2008), where increasing iron in iron-limited regions (for example the Southern Ocean), exports more phosphorus and other nutrients, and reduces the lateral advection and possibly the upwelling of phosphorus and other nutrients in downstream regions, and 

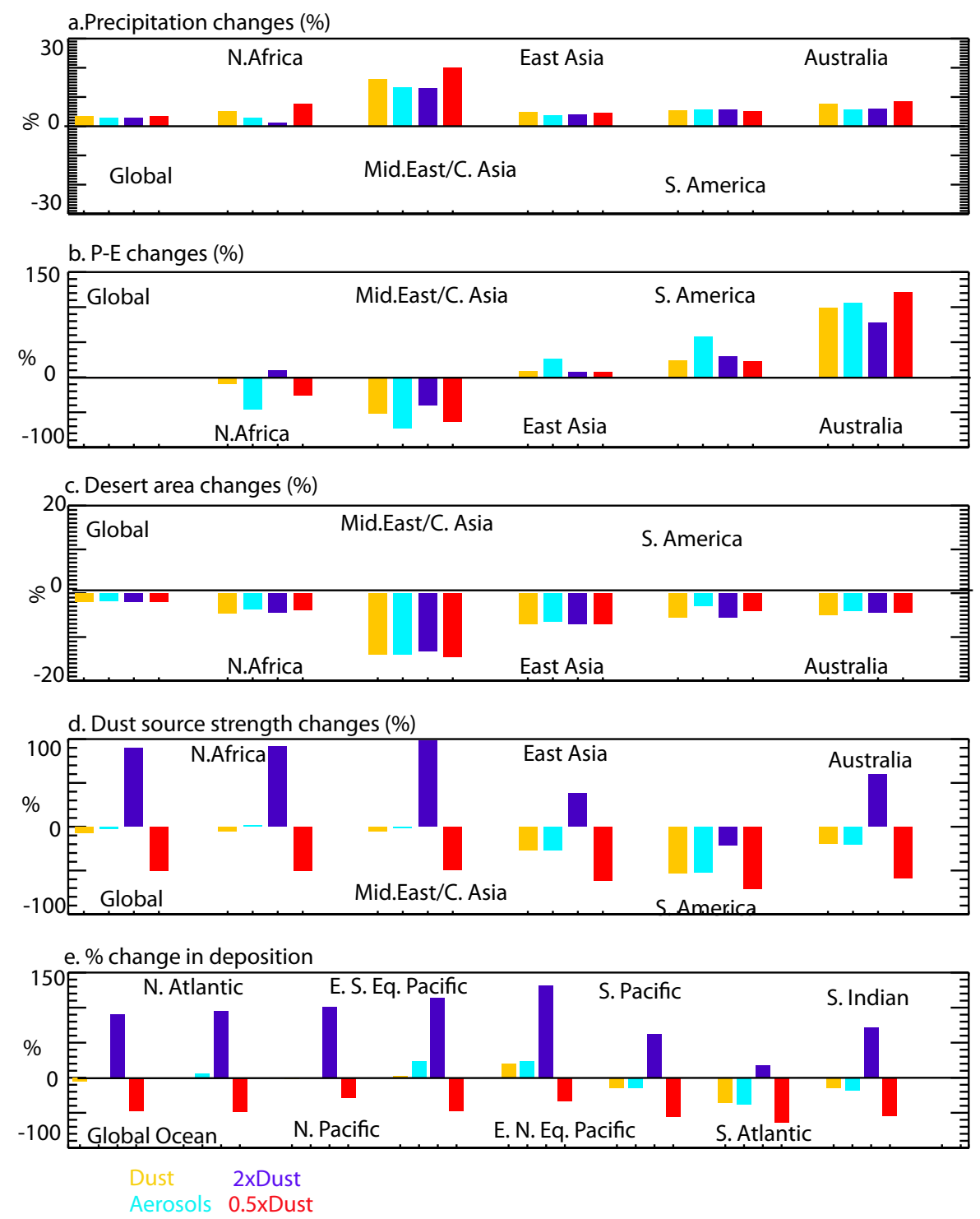

Fig. 14. Percent changes in source areas (a), precipitation (b), precipitation minus evaporation (c), desert area (d), dust source strength (e) and deposition in ocean basins (e) for 2080-2099 compared to preindustrial control for the different cases. Eastern S. Eq. Pacific is defined as 220 E-280 E, 20 S-0 N; eastern N. Eq. Pacific is defined as 220 E-280 E, 0-20 N.

therefore reduces productivity in downstream regions. This downstream offsetting reduces the integrated ocean carbon cycle response to higher iron inputs (seen also in Krishnamurthy et al., 2009).

In our model simulations, changes in desert dust deposition force changes in ocean productivity, which are as large as the changes in productivity forced by $\mathrm{CO}_{2}$ increases (Fig. 4 and discussion in Sect. 3.1). A recent study evaluated the projected changes in marine productivity from several different coupled-carbon-climate models (Steinacher et al., 2010), and we contrast our results with theirs (Fig. 17). One model simulation from this study was included in Steinacher, et al. (2010) (BASE1). Overall, changes in desert dust sig- nificantly change productivity in the Northern mid-latitudes, equatorial regions and Southern Ocean $(\sim 40-50 S)$, and these changes are often of a similar size as the spread in the different models. This suggests that projections of marine productivity changes should include the impacts of changes in desert dust and aerosols.

\subsection{Carbon and climate impacts on aerosol lifetimes}

The atmospheric lifetime of an aerosol is defined as the amount of aerosol divided by the deposition flux, and for the sulfur compounds and dust, these are prognostically calculated in the model for the AEROSOL case. One can 
a. BASE (2080-2099 vs. PI)
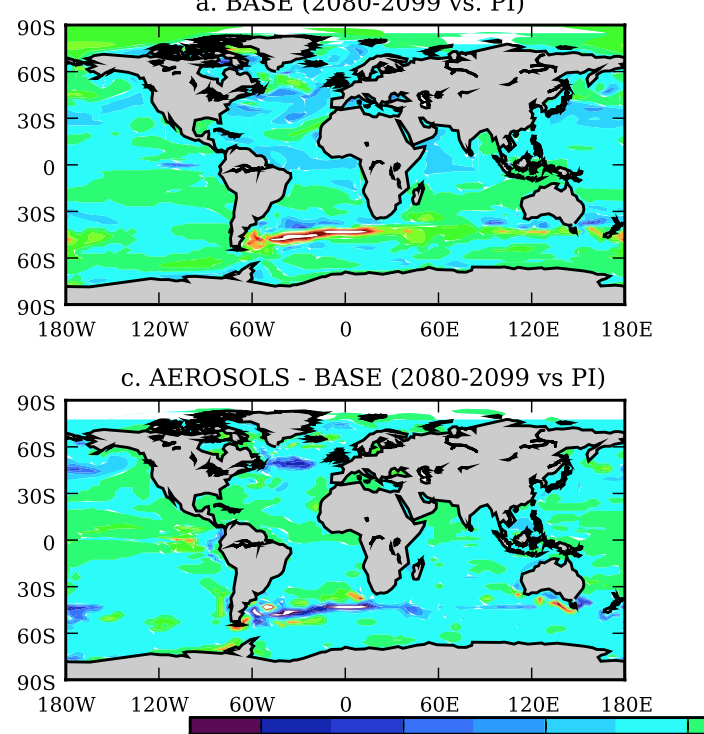

b. DUST - BASE (2080-2099 vs PI)

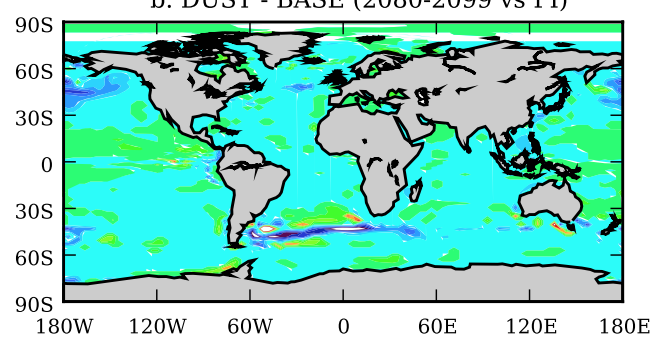

d. 2xDUST - 0.5xDUST (2080-2099)

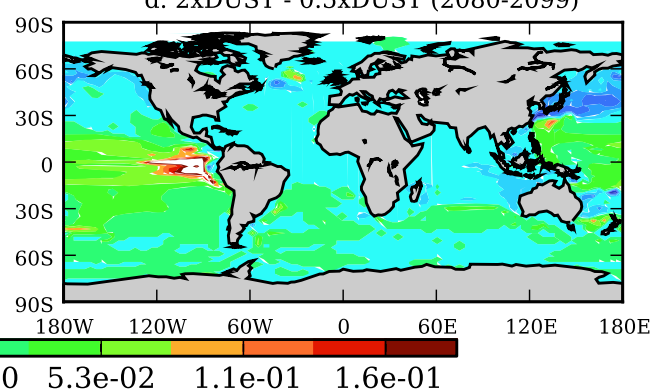

Fig. 15. Same as Fig. 11 but for the total chlorophyll $\left(\mathrm{mg} \mathrm{Chl} \mathrm{m}^{-3}\right)$ in the mixed layer.

Table 2. Evolution of aerosol lifetime with climate and carbon dioxide changes (days).

\begin{tabular}{|c|c|c|c|c|}
\hline Time period & Model case & $\mathrm{SO}_{2}$ & $\mathrm{SO}_{4}$ & Dust \\
\hline \multicolumn{5}{|c|}{ Overall lifetime of aerosols } \\
\hline 1870s & AEROSOL & 5.82 & 3.56 & 4.48 \\
\hline 2090s & AEROSOL & 3.46 & 3.88 & 4.63 \\
\hline 1870s & AEROSOL-r & 5.82 & 3.56 & 4.52 \\
\hline 2090s & AEROSOL-r & 3.51 & 3.78 & 4.67 \\
\hline \multicolumn{5}{|c|}{ Dry deposition lifetime } \\
\hline 1870s & AEROSOL & 6.24 & 30.28 & 6.32 \\
\hline 2090s & AEROSOL & 3.58 & 28.66 & 6.43 \\
\hline 1870s & AEROSOL-r & 6.24 & 30.22 & 6.38 \\
\hline 2090s & AEROSOL-r & 3.62 & 28.43 & 6.55 \\
\hline \multicolumn{5}{|c|}{ Wet deposition lifetimes } \\
\hline 1870s & AEROSOL & 86.6 & 4.04 & 15.4 \\
\hline 2090s & AEROSOL & 102.4 & 4.49 & 16.6 \\
\hline 1870s & AEROSOL-r & 86.8 & 4.04 & 15.5 \\
\hline 2090s & AEROSOL-r & 110.5 & 4.37 & 16.2 \\
\hline
\end{tabular}

also separate this lifetime by the process that removes the aerosol, wet deposition (during precipitation) or dry deposition. Shifts in winds, vertical mixing, precipitation, or source regions can change the lifetimes of aerosols. Changes in surface fluxes, due to changes in the plant properties at the land surface, could also change dry deposition rates. In addition, increases in carbon dioxide could change dry deposi- tion rates onto plants because of changes in stomatal conductance; however this process is not included in these simulations. Lifetimes due to the physical removal of $\mathrm{SO}_{2}, \mathrm{SO}_{4}$ and dust for the 1870s and 2090s are contrasted (Table 2). Notice that $\mathrm{SO}_{2}$ can also be chemically converted to $\mathrm{SO}_{4}$, and we do not analyze this process here. We can contrast simulations that include the climate change from aerosols and $\mathrm{CO}_{2}$ (AEROSOLS) and those which include just the impacts from changing in aerosols (AEROSOLS-r). For $\mathrm{SO}_{2}$, the dominant removal process is dry deposition $\left(\mathrm{SO}_{2}\right.$ is converted to $\mathrm{SO}_{4}$ in clouds, so this process will be important in the presence of clouds). The lifetime shortens between $1870 \mathrm{~s}$ and 2090s (5.82 to 3.46 days), suggesting that changes in aerosol sources or direct impacts of higher $\mathrm{CO}_{2}$ onto vegetation are most important. For sulfate, the lifetime lengthens slightly, largely due to wet deposition lifetime changes. Again, this signal is similar with and without climate change from $\mathrm{CO}_{2}$. For dust, dry deposition dominates (because of the relatively large size of dust particles), and the lifetime is slightly longer (less than 10\%) in the 2090s than 1870s (4.48 vs. 4.63). The dry deposition lifetime is slightly longer in 2090s (less than 10\%) (6.55 vs. 6.43) when $\mathrm{CO}_{2}$ is impacting climate (AEROSOLS-r) vs. not impacting climate. This suggests that most of the changes in lifetime in these simulations are due to changes in sources or changes in vegetation from direct $\mathrm{CO}_{2}$ fertilization, since the changes are similar whether or not $\mathrm{CO}_{2}$ is impacting climate. 

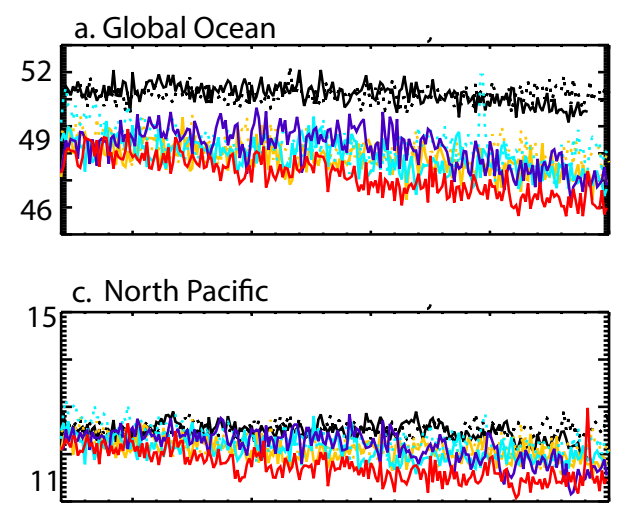

e. E. N. Eq. Pacific
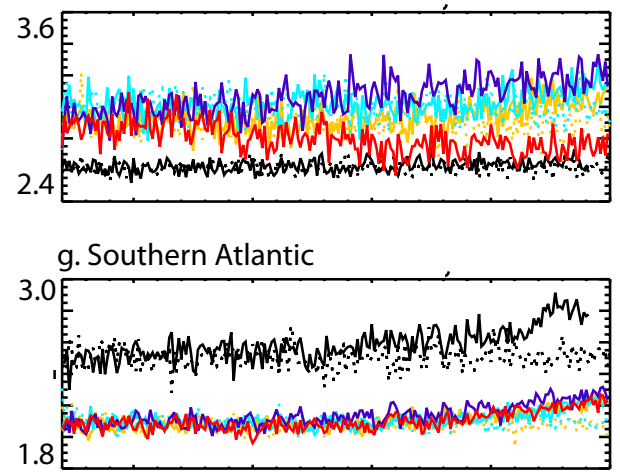

i. Indian

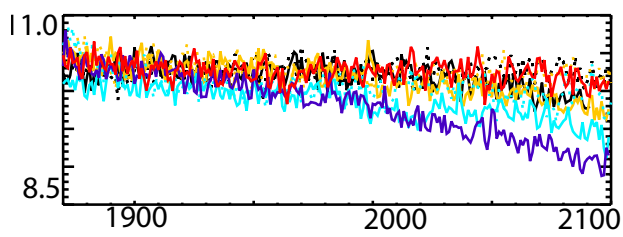

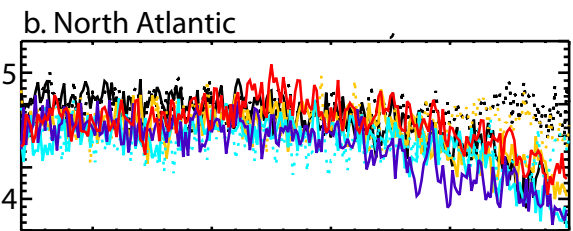

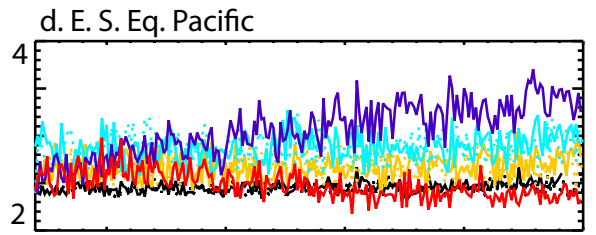

f. Southern Pacific
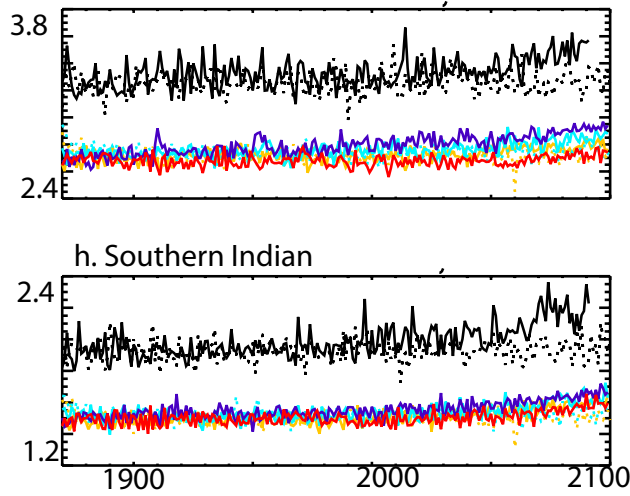

Base1

Dust

Aerosols

$2 \times$ Dust

$0.5 \times$ Dust

Fig. 16. Times series of ocean productivity in different regions of the ocean from 1870 to 2100 for the cases in Table 1 . Regions are as in Fig. 14e. Note that different panels have different scaling.

\section{Summary and conclusions}

The sensitivity studies conducted in this study suggest that there can be regionally significant changes in climate and some changes in carbon fluxes, either when the preindustrial control is out of balance at the beginning of the transient simulations (by $\sim 0.09 \mathrm{PgC} \mathrm{year}^{-1}$ in our case), or changing between having fully 3-dimensional prognostic $\mathrm{CO}_{2}$ which can contain strong surface gradients (as usually done with this model) versus a globally averaged value (e.g. used in the Friedlingstein et al., 2003 study). However, the globally averaged climate and carbon is not significantly perturbed.

For the first time, we include the interactions of desert dust on the climate and biogeochemistry in a fully coupledcarbon-climate model. In addition we include anthropogenic aerosol evolution similar to Jones et al. (2003). Our results suggest a much lower sensitivity to the inclusion of aerosols than seen in Jones et al. (2003). We argue that much of the difference between this study and this previous study using HADCM3LC can be explained by the difference in global climate forcing and feedbacks onto the carbon cycle (Fig. 7). The CCSM3.1 model has a slightly negative sensitivity to climate (i.e., more climate change means more carbon is taken up), due partly to the $\mathrm{N}$-limitation in the land model, and partly due to a slow uptake by the oceans (Thornton et al., 2009). This result is in contrast to the carbon-only models previously compared (Friedlingstein et al., 2006), especially to the model used in Jones et al. (2003), which has a strong climate impact onto the carbon cycle. Our results, combined with the previous results (Jones et al., 2003) suggest that the impact of aerosols onto the coupled-climate-carbon cycle may be largely explained by the globally averaged cooling from the aerosols, and is proportional to the climate impact on the carbon cycle (Fig. 7c). We propose that a simple change to the simple feedback analysis of Friedlingstein et 


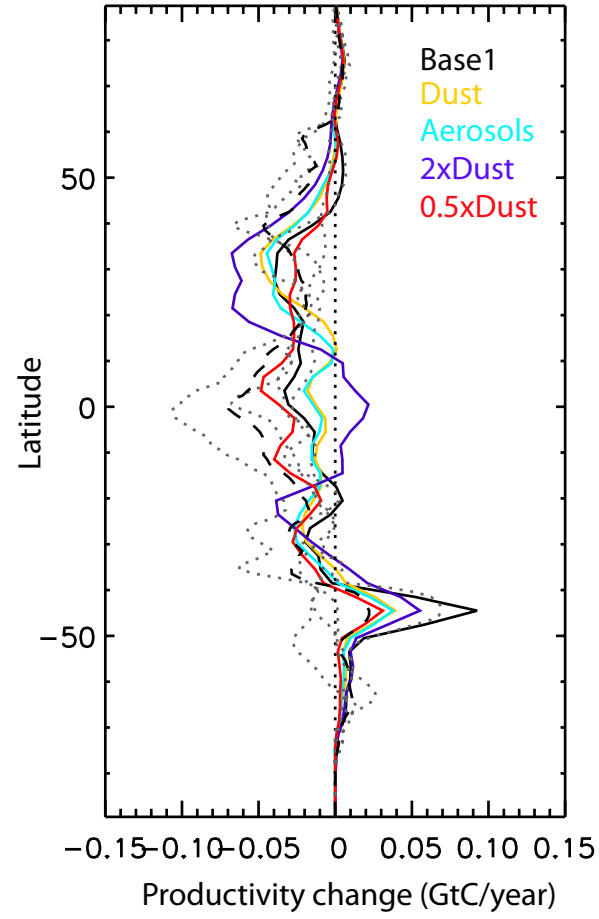

Fig. 17. Zonally averaged ocean productivity changes (2080-2099 compared to 1870-1889) from the simulations presents here (color and solid black lines), compared to the results from (Steinacher et al., 2010) (mean: dotted black, various models: dotted black).

al. (2006) can account for the majority of the globally averaged impact of aerosols in coupled-carbon-climate models. However, there are globally significant changes in carbon which can not be explained by the globally averaged cooling from aerosols, which are likely to be due to changes in regional climate driven by aerosols, or by changes in diffuse and direct radiation (e.g. Mercado et al., 2009). Inclusion of aerosols statistically significantly changes the regional climate and biogeochemistry predictions of the model.

Inclusion of realistic desert dust cycling does significantly impact the ocean biogeochemistry in our simulations, in terms of the nitrogen fixation and the ocean productivity. Our model includes iron limitation to phytoplankton growth, as well as a larger iron requirement for $\mathrm{N}$-fixing organisms, making our iron and nitrogen cycles linked. Changes in desert dust significantly impact productivity and the nitrogen cycle of the ocean (Figs. 4 and 17), and having interactive dust and anthropogenic aerosols is as important or more important as changes in carbon dioxide and the resulting climate changes to the nitrogen cycle and productivity in our model (Fig. 4 and Sect. 3.1). This becomes even more true if desert dust has doubled over the past 100 years, as recently estimated (e.g. Mulitza et al., 2010; Mahowald et al., 2010), and continues to increase. Interestingly, many changes to ocean biogeochemistry seem to occur due to physical forc- ing of climate by aerosols instead of purely from the addition of iron: this should be further explored in future studies. Note that this model includes only the physical forcing of higher $\mathrm{CO}_{2}$ onto ocean biogeochemistry and does not include changes in ocean biogeochemistry that directly result from changes in ocean uptake in $\mathrm{CO}_{2}$, which are thought to be large (Hutchins et al., 2009).

There are many uncertainties in this generation of coupledcarbon-climate models, and an inclusion of more processes, such as done here and in Thornton et al. (2009), may lead to an increase in our perceived uncertainty in climate change estimates. Refinement of these models requires substantial effort of model inter-comparisons and comparison to observations to better understand how the terrestrial and ocean carbon cycles will respond to greenhouse gas and aerosol changes.

\section{Appendix A}

\section{A1 Description of desert dust simulation}

As described in the methods section, the desert dust module from (Mahowald et al., 2006a; Yoshioka et al., 2007) was incorporated into the coupled-carbon-climate model (Thornton et al., 2009). Here we briefly show the results from the desert dust model. The model aerosol optical depth was 0.024 , similar to the observationally-based estimates (Reddy et al., 2005). A comparison of the modeled atmospheric surface concentration and deposition to available data (Figs. A1 and A2), shows that the model is able to capture the variability in dust concentrations and depositions over the 4 orders of magnitude seen over the globe.

\section{A2 Carbon cycle supplement}

Additionally slides describing the impact of aerosols at 2030-2049 compared to preindustrial climate for the surface temperature (A3) and carbon dioxide flux (Fig. A4) demonstrate that while the impact of aerosols at 2030-2049 is more than at 2080-2099 (shown in main text), the carbon dioxide signal dominates.

The impact of not removing the control fluxes demonstrates that even slowly varying simulations (such as our BASE or AEROSOL case) contains statistically significant carbon fluxes which disappear when the control simulation fluxes (at the same time from the beginning of the transient simulation) are subtracted (compare Fig. A5 to Fig. 10).

The relationship between $\mathrm{CO}_{2}$ and temperature in these simulations is more linear than log (Fig. A6).

The differences in changes in mixed layer depths in the ocean is shown in Eq. (A7), in order to contrast with the chlorophyll figures shown in the main text and discussed in the main text. 

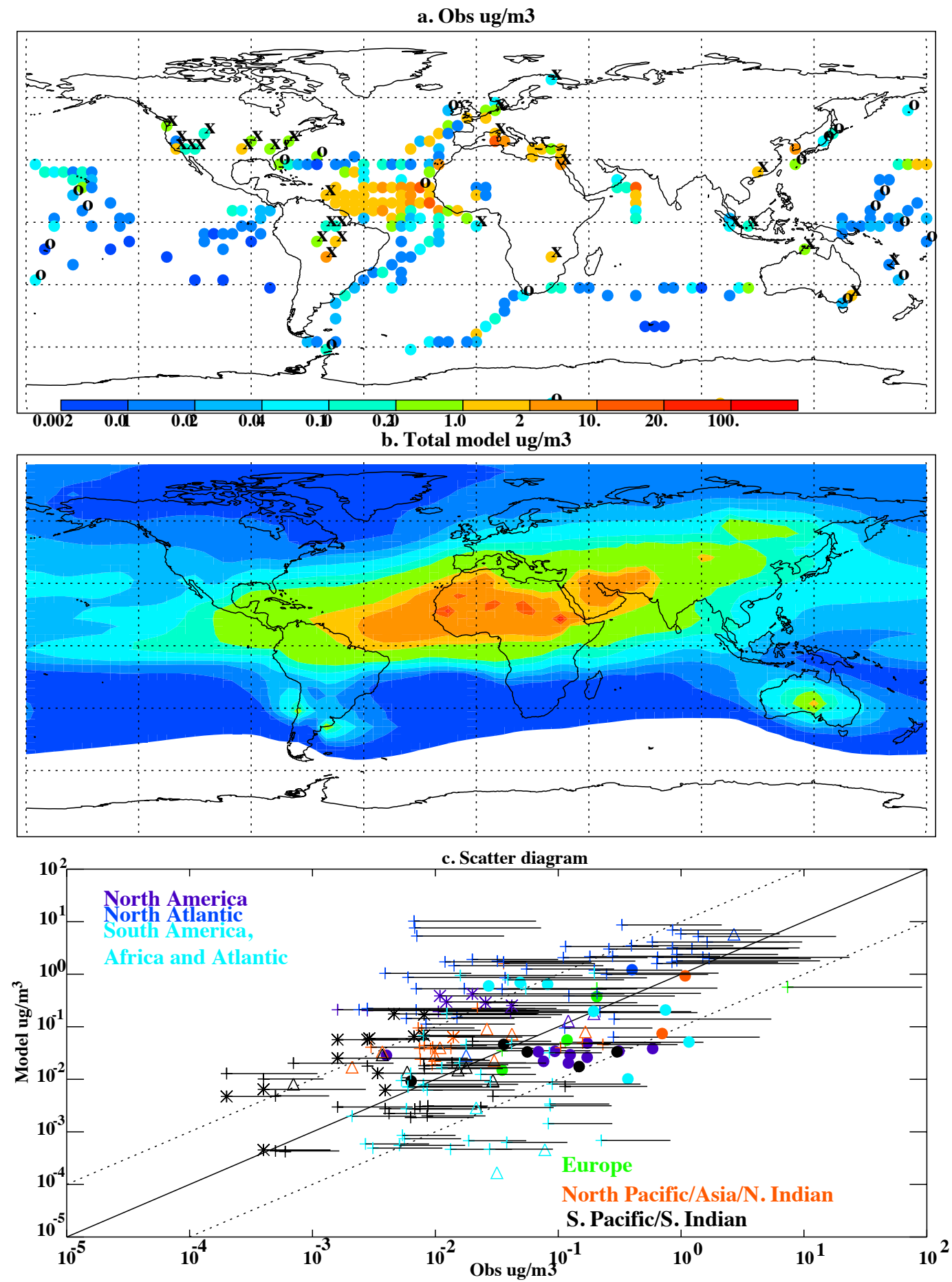

Fig. A1. Annual atmospheric surface iron concentration measurements (a) compared to model estimates (based on $3.5 \%$ iron in desert dust) (b), and shown in scatterplot format (c). The data compilation comes from (Mahowald et al., 2009). The horizontal lines represent the uncertainties in the model because the observations are taken from cruises, and include only 1-2 days, while the model shows annual averages (described in more detail in Mahowald et al., 2008). 
a. Obs Fe g/m2/year

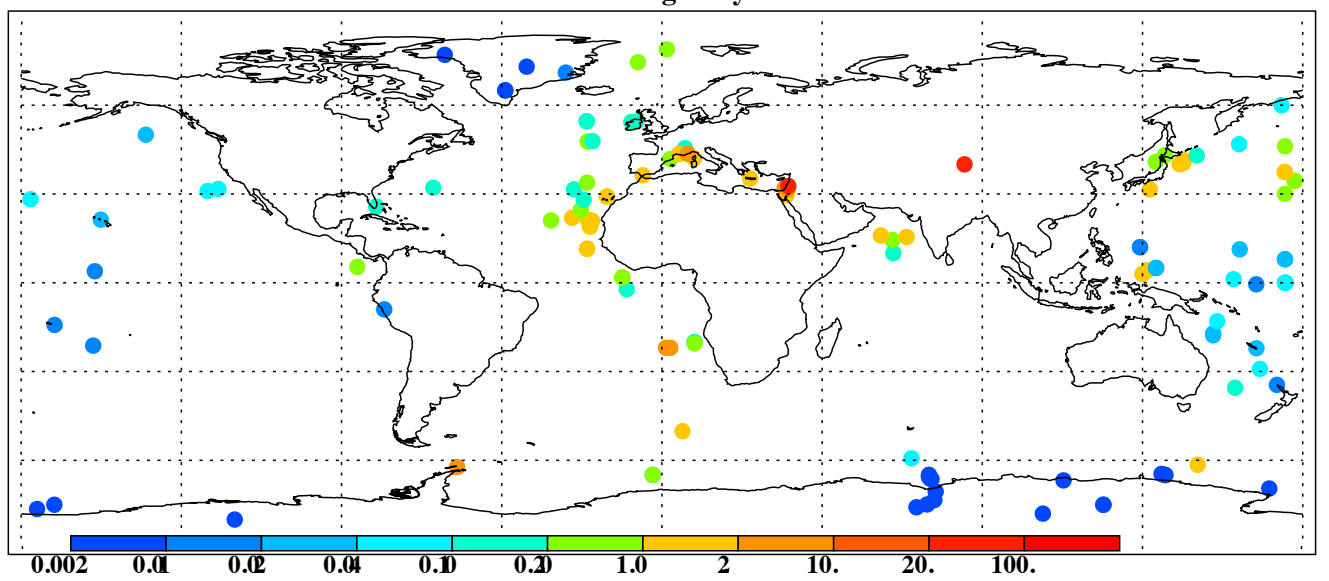

b. Total model Fe g/m2/year
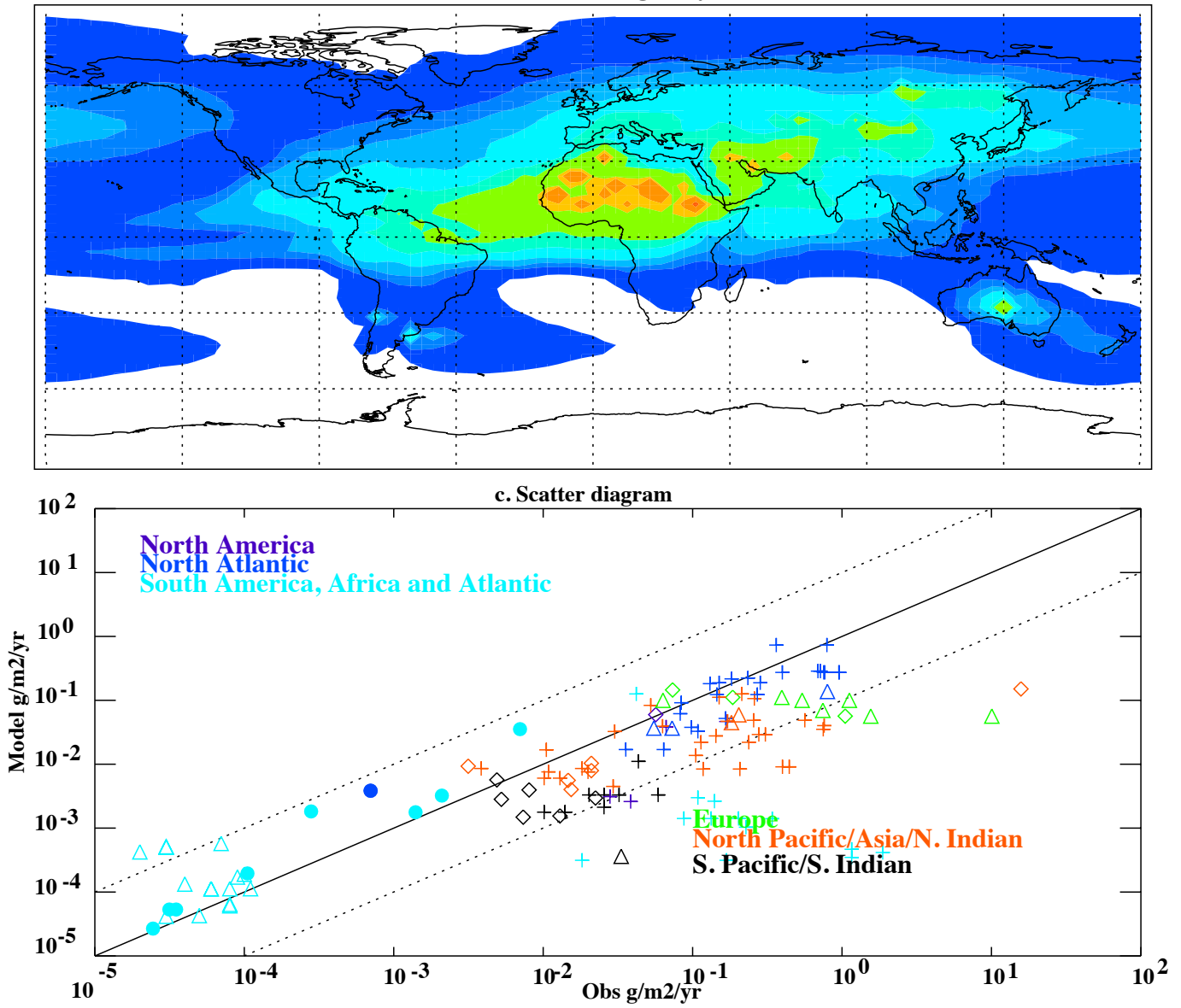

Fig. A2. Iron deposition rates from available measures (a) compared to model estimates (based on 3.5\% iron in desert dust) (b), and shown in scatterplot format (c). The data compilation comes from (Mahowald et al., 2009). 

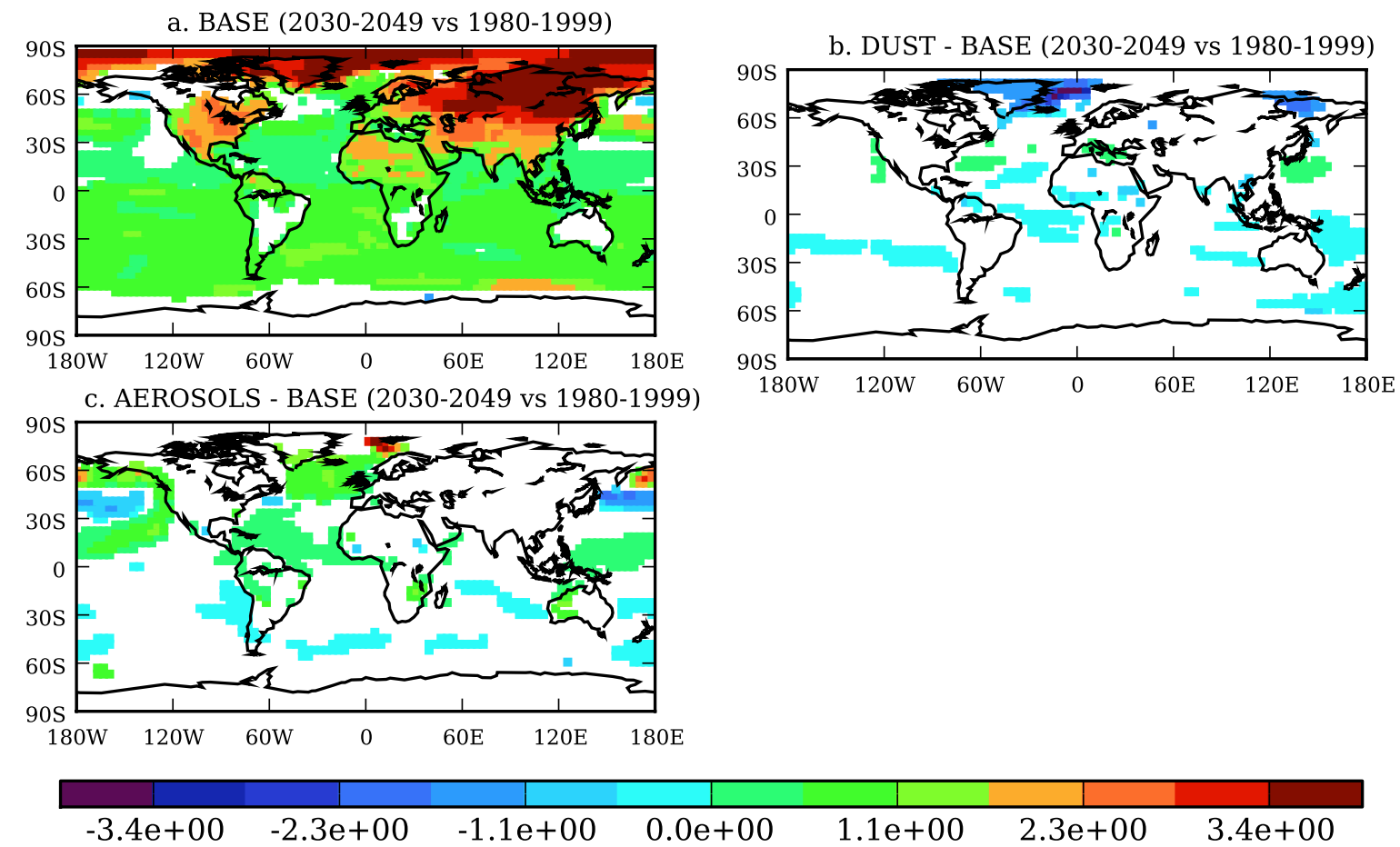

Fig. A3. Surface temperature (K) differences for 2030-2049 relative to 1980-1999 control for each case: (a) mean change for 3 ensemble BASE case members, (b) differences from BASE case differences for interactive dust (DUST), (c) differences from BASE case for interactive aerosols (AEROSOL). Only changes significant at the 95\% level are shown in color. Note that panels (b), and (c) show differences from the 3 BASE case differences from preindustrial (for example: (DUST2030-2049 minus DUST-control) minus (BASE2030-2049 minus BASE-control)).
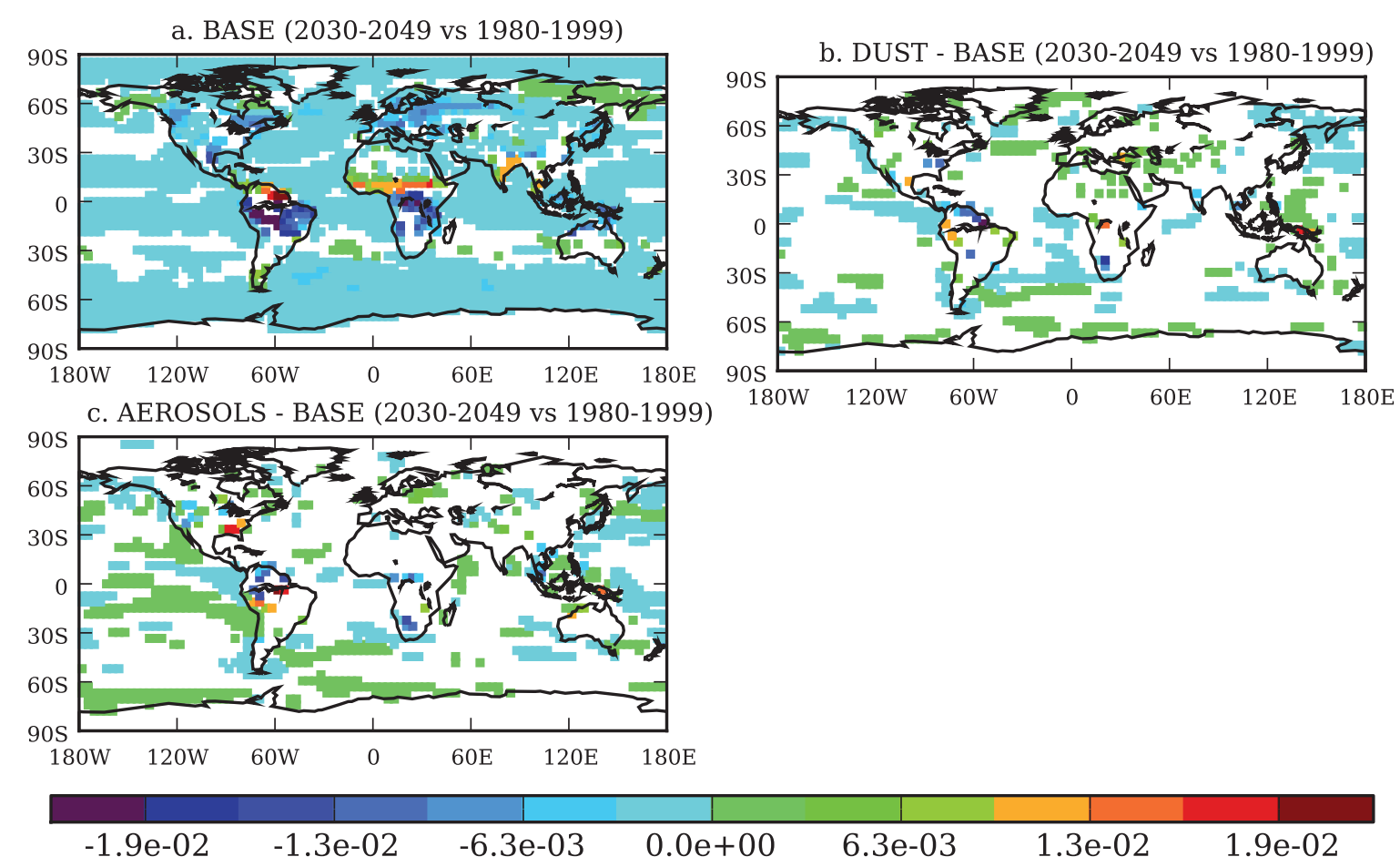

Fig. A4. Same as Fig. A3, but for surface $\mathrm{CO}_{2}$ fluxes $\left(\mathrm{mg} \mathrm{CO}_{2} \mathrm{~m}^{-2} \mathrm{~s}^{\circ}\right)$. 

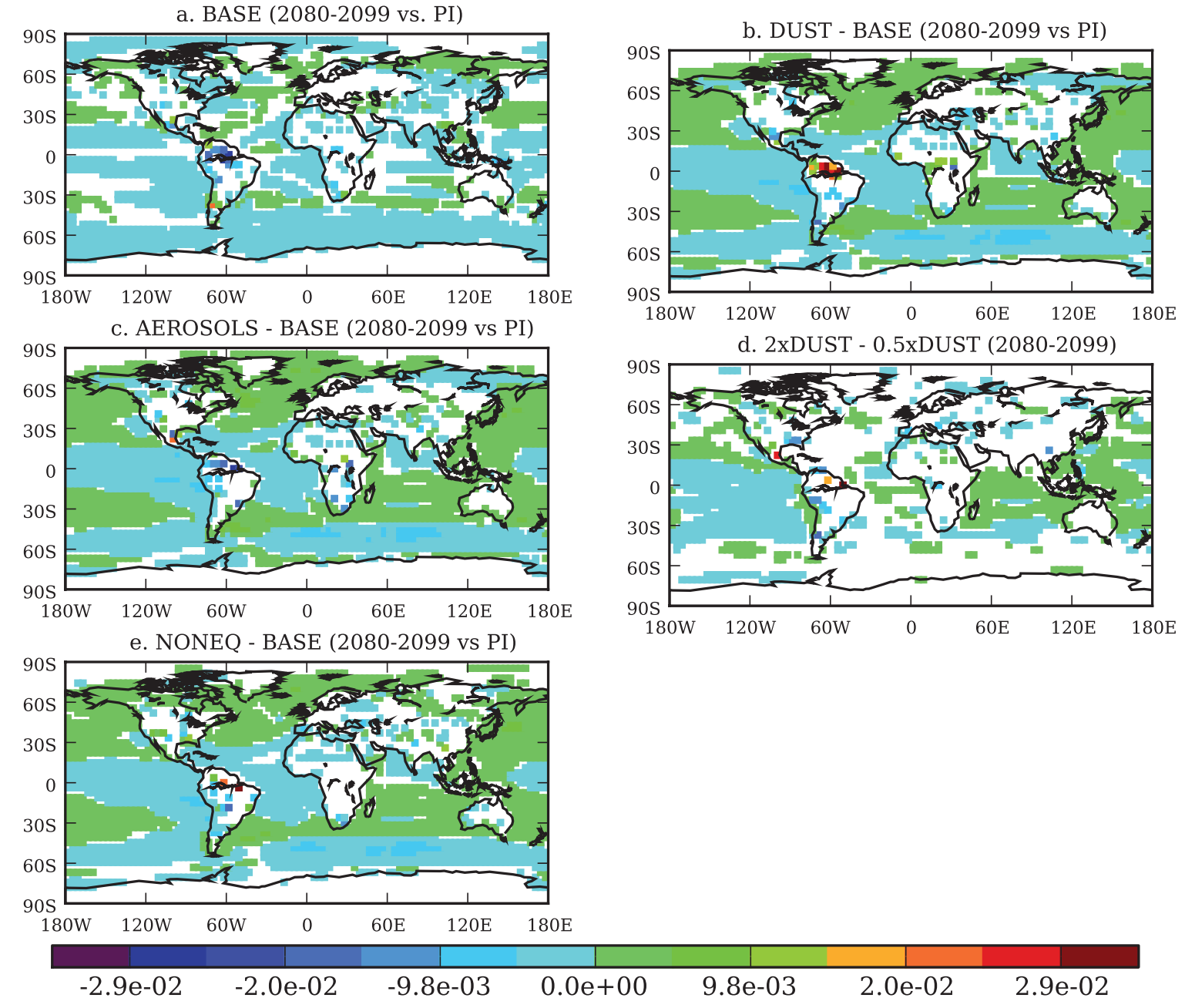

Fig. A5. Surface $\mathrm{CO}_{2}$ flux ( $\mathrm{mg} \mathrm{CO} \mathrm{CO}^{-2} \mathrm{~s}^{-1}$ ) differences for 2080-2099 versus the first twenty years of the same simulation for each case: (a) mean change for 3 ensemble base case members, (b) differences from base case differences for interactive dust (DUST), (c) differences from base case for interactive aerosols (AEROSOL), (d) difference between $2 \times$ DUST and 0.5DUST cases, (e) differences from base case for case of NONEQ, and (f) differences from base for case of TRAJ. Only changes significant at the 95\% level are shown in color. Note that panels (b), (c), (e) and (f) show differences from the 3 BASE case differences from the beginning of the simulation (for example: (DUST2080-2099 minus DUST-1870-1889) minus (BASE2080-2099 minus BASE-1870-1889)). This figure is the same as Fig. 10 in the main text, but without removing any drift in the control simulation.

\section{a. $\mathrm{CO}_{2}$ vs. delta $\mathrm{T}$}

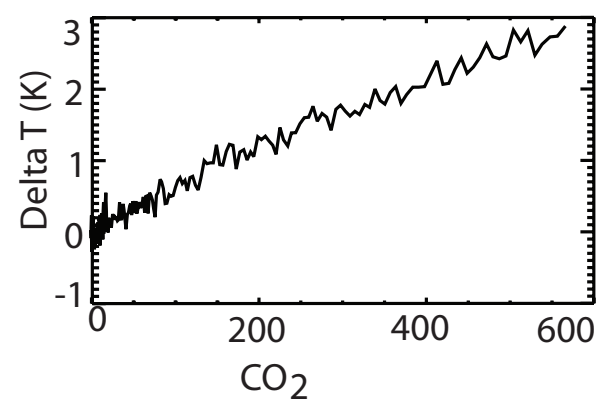

b. $\log \left(\mathrm{CO}_{2}\right)$ vs. delta T

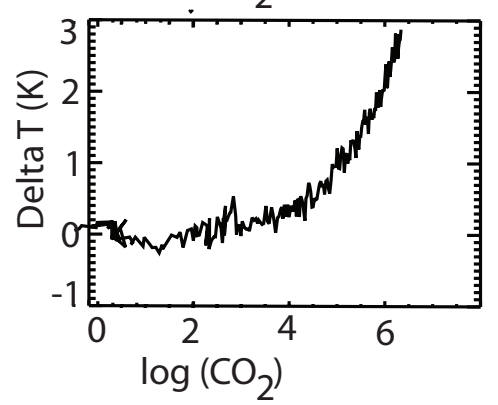

Fig. A6. The modeled relationship between temperature and carbon dioxide in the BASE1 case (a), and plotted instead using a log relationship (b). 

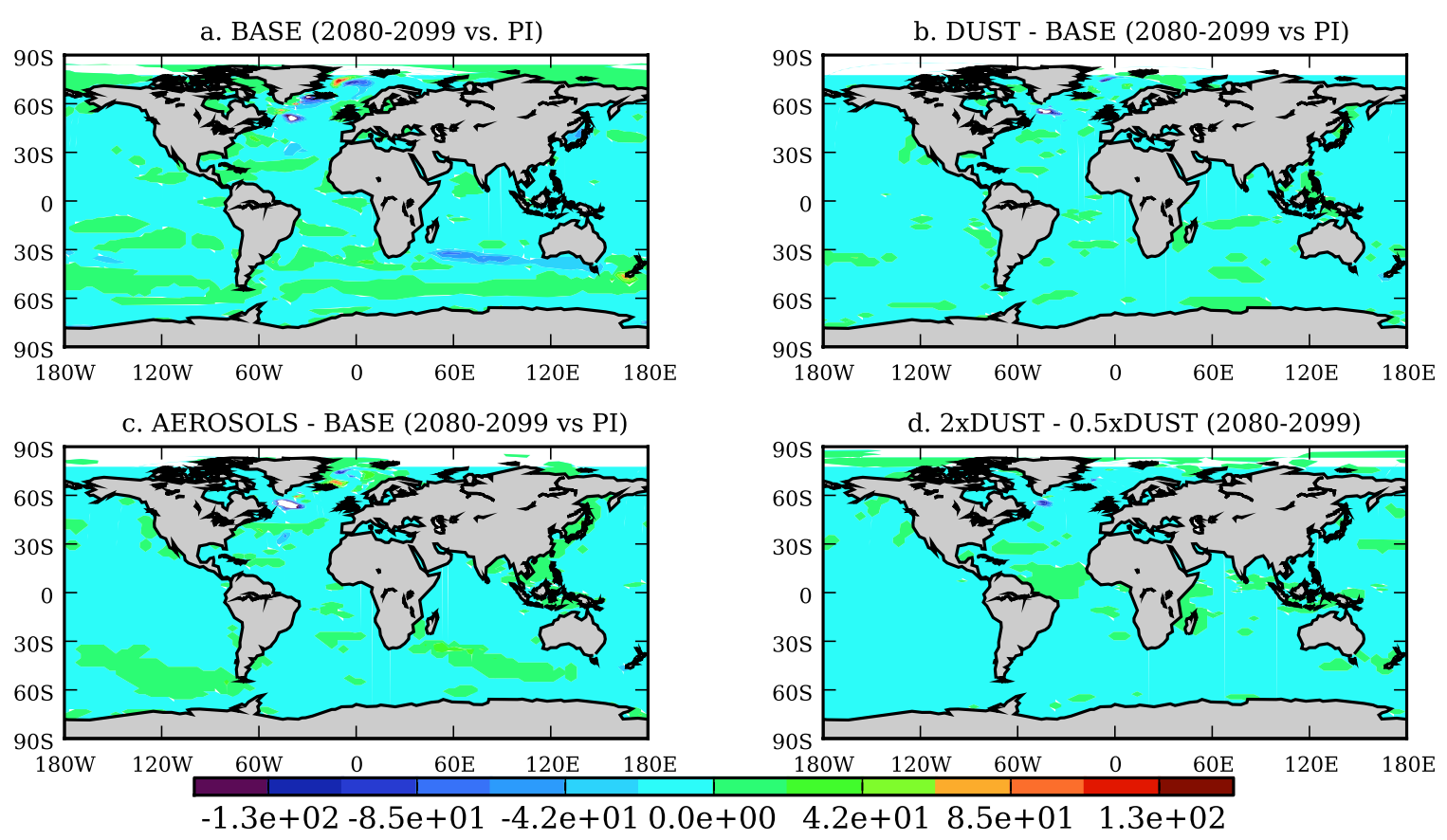

Fig. A7. Ocean mixed layer depth (m) differences for 2080-2099 versus the first twenty years of the same simulation for each case: (a) mean change for 3 ensemble base case members, (b) differences from base case differences for interactive dust (DUST), (c) differences from base case for interactive aerosols (AEROSOL), (d) difference between $2 \times$ DUST and 0.5DUST cases, (e) differences from base case for case of NONEQ, and (f) differences from base for case of TRAJ. Only changes significant at the $95 \%$ level are shown in color. Note that panels (b), (c), (e) and (f) show differences from the 3 BASE case differences from the beginning of the simulation (for example: (DUST2080-2099 minus DUST-1870-1889) minus (BASE2080-2099 minus BASE-1870-1889)).

Acknowledgements. This work was done under the auspices of NASA NNG06G127G, NSF grants 0748369, 0932946, 0745961 and 0832782. The work of C. J. was supported by the Joint DECC/Defra Met Office Hadley Centre Climate Programme (GA01101). Computer time was obtained from the National Center for Atmospheric Research, a National Science Foundation facility. We thank Marco Steinacher and Fortunat Joos for making available figure data from their paper. We thank Inez Fung and Pierre Friedlingstein for conversations contributing to this paper. We thank two anonymous reviewers and Fortunat Joos for comments on the manuscript.

Edited by: F. Joos

\section{References}

Cadule, P., Bopp, L., and Friedlingstein, P.: A revised estimate of the processes contributing to global warming due to climate-carbon feedback, Geophys. Res. Lett., 36, L14705, doi:1029/2009GL038681, 2009.

Collins, W., Bitz, C., Blackmon, M., Bonan, G., Bretherton, C., Carton, J., Chang, P., Doney, S., Hack, J., Henderson, T., Kiehl, J., Large, W., McKenna, D., Santer, B., and Smith, R.: The community climate system model: CCSM3, J. Climate, 19, 21222143, 2006a.
Collins, W. D., Rasch, P. J., Boville, B. A., Hack, J. J., McCaa, J. R., L.Williamson, D., Briegleb, B. P., Bitz, C. M., Lin, S.-J., and Zhang, M.: The formulation and atmospheric simulation of the Community Atmosphere Model, CAM3., J. Climate, 19, 2144 2161, 2006b.

Cox, P., Betts, R., Jones, C., Spall, S., and Totterdell, I.: Acceleration of global warming due to carbon cycle feedbacks in a coupled climate model, Nature, 408, 184-187, 2000.

Cox, P., Harris, P., Huntingford, C., Betts, R., Collins, M., Jones, C., Jupp, T., Marengo, J., and Nobre, C.: Increasing risk of Amazonian drought due to decreasing aerosol pollution, Nature, 453, 212-216, doi:10.1038/35041539, 2008.

Denman, K. L., Brasseur, G., Chidthaisong, A., Ciais, P., Cox, P. M., Dickinson, R. E., Hauglustaine, D., Heinze, C., Holland, E., Jacob, D., Lohmann, U., Ramachandran, S., Dias, P. L. d. S., Wofsy, S. C., and Zhang, X.: Couplings between changes in the climate system and biogeochemistry, in: Climate Change 2007: The Physical Science Bases. Contribution of Working Group I to the Fourth Assessment Report of the Intergovernmental Panel on Climate Change, edited by: Solomon, S., Qin, D., Manning, M., Chen, Z., Marquis, M., Averyt, K. B., Tignor, M., and Miller, H. L., Cambridge University Press, Cambridge, UK, 2007.

Denning, A. S., Fung, I. Y., and Randall, D.: Latitudinal gradient of atmosphere $\mathrm{CO}_{2}$ due to seasonal exchange with land biota, Nature, 376, 240-243, 1995.

Doney, S. C., Lindsay, K., Fung, I., and John, J.: Natural variability in a stable 1000 year coupled climate-carbon cycle simulation, 
J. Climate, 19(13), 3033-3054, 2006.

Doney, S., Lima, I., Feeley, R., Glover, D., Lindsay, K., Mahowald, N., Moore, J. K., and Wanninkhof, R.: Mechanisms governing interannual variability in upper-ocean inorganic carbon system and air-sea $\mathrm{CO}_{2}$ fluxes: physical climate and atmospheric dust, Deep Sea Res. Pt. II: Topical Studies in Oceanography, 56, 640655, 2009a.

Doney, S., Lima, I., Moore, J. K., Behrenfeld, M., Mahowald, N., Maltrud, M., Glober, D., McGillicuddy, D., and Takahashi, T.: Skill metrics for confronting global upper ocean ecosystem biogeochemistry models against field and remote sensing data, J. Mar. Sci., 76, 95-112, 2009 b.

Doney, S. C., Fabry, V. J., Feely, R. A., and Kleypas, J. A.: Ocean acidification: the other $\mathrm{CO}_{2}$ problem, Ann. Rev. Mar. Sci., 1, 169-192, 2009c.

Elrod, V. A., Berelson, W. M., Coale, K. H., and Johnson, K. S.: The flux of iron from continental shelf sediments: A missing source of global budgets, Geophys. Res. Lett., 31, L12307, doi:10.1029/2004GL020216, 2004.

Falkowski, P. G., Barber, R. T., and Smetacek, V.: Biogeochemical Controls and Feedbacks on Ocean Primary Production, Science, 281, 200-206, 1998.

Forster, P., Ramaswamy, V., Artaxo, P., Berntsen, T., Betts, R., Fahey, D. W., Haywood, J., Lean, J., Lowe, D. C., Myhre, G., Nganga, J., Prinn, R., Raga, G., Schulz, M., and Dorland, R. V.: Changes in Atmospheric Constituents and in Radiative Forcing, in: Climate Change 2007: The Physical Science Basis, Contribution of Working Group I to the Fourth Assessment Report of the Intergovernmental Panel on Climate Change, edited by: Solomon, S., Qin, D., Manning, M., Chen, Z., Marquis, M., Averyt, K. B., Tignor, M., and Miller, H. L., Cambridge University Press, Cambridge, UK and New York, NY, USA, 130-234, 2007.

Friedlingstein, P., Dufresne, J.-L., Cox, P. M., and Rayner, P.: How positive is the feedback between climate change and the carbon cycle?, Tellus, 55B, 692-700, 2003.

Friedlingstein, P., Cox, P., Betts, R., Bopp, L., Von Bloh, W., Brovkin, V., Cadule, P., Doney, S., Eby, M., Fung, I., Bala, G., John, C., Jones, C., JOOS, F., Kato, T., Kawamiya, M., Knorr, W., Lindsay, K., Matthews, H. D., Raddatz, T., Rayner, P., Reick, C., Roeckner, E., Schnitzler, K.-G., Schnur, R., Strassmann, K., Weaver, A. J., Yoshikawa, C., and Zeng, N.: Climate-carbon cycle feedback analysis, results from the C4MIP Model intercomparison, J. Climate, 19, 3337-3353, 2006.

Fung, I., Doney, S., Lindsay, K., and John, J.: Evolution of carbon sinks in a changing climate, Proceedings of National Academy of Science, 102, 11201-11206, 2005.

Gillette, D. A.: Threshold friction velocities for dust production for agricultural soils, J. Geophys. Res., 93, 12, 645-612, 662, 1988.

Hansen, J., Sato, M., Ruedy, R., Nazarenko, L., Lacis, A., Schmidt, G. A., Russell, G., Aleinov, I., Bauer, M., Bauer, S., Bell, N., Cairns, B., Canuto, V., Chandler, M., Cheng, Y., Del Genio, A., Faluvegi, G., Fleming, E., Friend, A., Hall, T., Jackman, C., Kelley, M., Kiang, N., Koch, D., Lean, J., Lerner, J., Lo, K., Menon, S., Miller, R., Minnis, P., Novakov, T., Oinas, V., Perlwitz, Ja., Perlwitz, Ju., Rind, D., Romanou, A., Shindell, D., Stone, P., Sun, S., Tausnev, N., Thresher, D., Wielicki, B., Wong, T., Yao, M., and Zhang, S. : Efficacy of climate forcings, J. Geophys. Res., 110, D18104, doi:10.1029/2005JD005776, 2005.

Huntingford, C., Lowe, J., Booth, B., Jones, C., Harris, G., Gohar,
L., and Mier, P.: Contributions of carbon cycle uncertainty to future climate projection spread, Tellus, 61B, 355-360, 2009.

Hutchins, d. A., Mulholland, M., and Fu, F.: Nutrient Cycles and Marine Microbes in a $\mathrm{CO}_{2}$-Enriched Ocean, Oceanography, 22, 128-145, 2009.

Johns, T. C., Gregory, J. M., Ingram, W. J., Johnson, C. E., Jones, A., Lowe, J. A., Mitchell, J. F. B., Roberts, D. L., Sexton, D. M. H., Stevenson, D., Tett, S. F. B., and Woodage, M. J.: Anthropogenic climate change for 1860 to 2100 simulated with the HadCM3 model under updated emissions scenarios, Clim. Dynam., 20, 583-612, 2003.

Jones, A., Roberts, D. L., Woodage, M., and Johnson, C.: Indirect sulphate aerosol forcing in a climate model with an interactive sulphur cylce, J. Geophys. Res., 106, 20293-20310, 2001.

Jones, C., Cox, P., Essery, R., Roberts, D., and Woodage, M.: Strong carbon cycle feedbacks in a climate model with interactive $\mathrm{CO}_{2}$ and sulphate aerosols, Geophys. Res. Lett., 30, 1479, doi:1410.1029/2003g10166867, 2003.

Kohfeld, K. E. and Harrison, S. P.: DIRTMAP: the geological record of dust, Earth Sci. Rev., 54, 81-114, 2001.

Krishnamurty, A., Moore, J. K., Mahowald, N., Luo, C., Doney, S., Lindsay, K., and Zender, C.: Impacts of increasing anthropogenic soluble iron and nitrogen deposition on ocean biogeochemistry, Global Biogeochem. Cy., 23, doi:10.1029/2008GB003440, 2009.

Lam, P. and Bishop, J.: The continental margin is a key sources of iron to the North Pacific Ocean, Geophys. Res. Lett., 35, L07608, doi:10.1029/2008GL033294, 2008.

Mahowald, N.: Anthropocence changes in desert area: sensitivity to climate model predictions, Geophys. Res. Lett., 34, L18817, doi:10.1029/2007GL030472, 2007.

Mahowald, N. M. and Luo, C.: A less dusty future?, Geophys. Res. Lett., 30, 1903, doi:10.1029/2003GRL017880, 2003.

Mahowald, N., Rivera, G., and Luo, C.: Comment on "Relative importance of climate and land use in determining present and future global soil dust emission”, Geophys. Res. Lett., 31, L24105, doi:10.1029/22004GL021272, 2004.

Mahowald, N., Muhs, D., Levis, S., Rasch, P., Yoshioka, M., and Zender, C.: Change in atmospheric mineral aerosols in response to climate: last glacial period, pre-industrial, modern and doubled-carbon dioxide climates, J. Geophys. Res., 111, D10202, doi:10210.11029/12005JD006653, 2006a.

Mahowald, N., Yoshioka, M., Collins, W., Conley, A., Fillmore, D., and Coleman, D.: Climate response and radiative forcing from mineral aerosols during the last glacial maximum, pre-industrial and doubled-carbon dioxide climates, Geophys. Res. Lett., 33, L20705, doi:10.1029/2006GL026126, 2006b.

Mahowald, N., Jickells, T. D., Baker, A. R., Artaxo, P., BenitezNelson, C. R., Bergametti, G., Bond, T. C., Chen, Y., Cohen, D. D., Herut, B., Kubilay, N., Losno, R., Luo, C., Maenhaut, W., McGee, K. A., Okin, G. S., Siefert, R. L., and Tsukuda, S.: The global distribution of atmospheric phosphorus deposition and anthropogenic impacts, Global Biogeochem. Cy., 22, GB4026, doi:10.1029/2008GB003240, 2008.

Mahowald, N., Engelstaedter, S., Chao Luo, Sealy, A., Artaxo, P. Benitez-Nelson, C., Bonnet, S., Chen, Y., Chuang, P. Y., Cohen, D. D., Dulac, F., Herut, B., Johansen, A. M., Kubilay, N., Losno, R., Maenhaut, W., Paytan, A., Prospero, J. M., Shank, L. M., and Siefert, R. L.: Atmospheric Iron deposition: Global distribution, 
variability and human perturbations, Annu. Rev. Marine Sci., 1, 245-278, doi:10.1146/annurev.marine.010908.163727, 2009.

Mahowald, N. M., Kloster, S., Engelstaedter, S., Moore, J. K., Mukhopadhyay, S., McConnell, J. R., Albani, S., Doney, S. C., Bhattacharya, A., Curran, M. A. J., Flanner, M. G., Hoffman, F. M., Lawrence, D. M., Lindsay, K., Mayewski, P. A., Neff, J., Rothenberg, D., Thomas, E., Thornton, P. E., and Zender, C. S.: Observed 20th century desert dust variability: impact on climate and biogeochemistry, Atmos. Chem. Phys., 10, 10875-10893, doi:10.5194/acp-10-10875-2010, 2010.

Martin, J., Gordon, R. M., and Fitzwater, S. E.: The case for iron, Limnol. Oceanogr., 36, 1793-1802, 1991.

Meehl, G., Washington, W., Santer, B., Collins, W., Arblaster, J., Hu, A., Lawrence, D., Teng, H., Buja, L., and Strand, W.: Climate change projections for the 21 st century and climate change commitment in the CCSM3, J. Climate, 19, 2597-2616, 2006.

Meehl, G. A., Stocker, T. F., Collins, W. D., Friedlingstein, P. Gaye, A. T., Gregory, J. M., Kitoh, A., Knutti, R., Murphy, J. M., Noda, A., Raper, S. C. B., Watterson, I. G., Weaver, A. J., and Zhao, Z.-C.: Global Climate Projections, in: Climate Change 2007: The Physical Science Basis, Contribution of Working Group I to the Fourth Assessment Report of the Intergovernmental Panel on Climate Change, edited by: Solomon, S., Qin, D., Manning, M., Chen, Z., Marquis, M., Averyt, K. B., Tignor, M., and Miller, H. L., Cambridge University Press, Cambridge, UK and New York, NY, USA, 2007.

Mercado, L., Bellouin, N., Stich, S., Boucher, O., Huntingford, C., Wild, M., and Wild, P.: Impacts of changes in diffuse radiation on the global land carbon sink, Nature, 458, doi:10.1038/nature07949, 01014-01018, 2009.

Moore, C. M., Mills, M., Milnes, A., Langois, R., Achterberg, E., Lochte, K., Geider, R., and LaRoche, J.: iron limits primary productivity during spring blooms development in the central North Atlantic, Glob. Change Biol., 12, 626-634, 2006.

Moore, J. K., Doney, S. C., and Lindsay, K.: Upper ocean ecosystem dynamics and iron cycling in a global threedimensional model, Global Biogeochem. Cy., 18, GB4028, doi:4010.1029/2004GB002220, 2004.

Moore, J. K., Doney, S. C., Lindsay, K., Mahowald, N., and Michaels, A. F.: Nitrogen fixation amplifies the ocean biogeochemical response to decadal timescale variations in mineral dust deposition, Tellus, 58B, 560-572, 2006.

Moore, J. K. and Braucher, O.: Sedimentary and mineral dust sources of dissolved iron to the world ocean, Biogeosciences, 5, 631-656, doi:10.5194/bg-5-631-2008, 2008.

Mulitza, S., Heslop, D., Pittauerova, D., Fischer, H., Meyer, I., Stuut, J.-B., Zabel, M., Mollenhauer, G., Collins, J., Kuhnert, H., and Schulz, M.: Increase in African dust flux at the onset of commercial agriculture in the Sahel region, Nature, 466, doi:10.1038/nature09213, 09226-09228, 2010.

Neff, J., Reynolds, R., Belnap, J., and Lamothe, P.: Multi-decadal impacts of grazing on soil physical and biogeochemical properties in southeast Utah, Ecol. Appl., 15, 87-95, 2005.

Okin, G.: A new model of wind erosion in the presence of vegetation, J. Geophys. Res.-Earth, 113, F02S10, doi:10.1029/2007JF000758, 2008.

Oschlies, A.: Impact of atmospheric and terrestrial $\mathrm{CO}_{2}$ feedbacks on fertilization-induced marine carbon uptake, Biogeosciences, 6, 1603-1613, doi:10.5194/bg-6-1603-2009, 2009.
Parekh, P., Dutkiewicz, S., Follows, M., and Ito, T.: Atmospheric carbon dioxide in a less dusty world, Geophys. Res. Lett., 33, L03610, doi:10.1029/2005GL025098, 2006.

Parekh, P., Joos, F., and Mueller, S.: A modelng assessment of the interplay between aeolian iron fluxes and iron-binding ligands in controlling carbon dioxide fluctuations during Antarctic warm events, Paleoceanography, 23, doi:1029/2007PA001531, 2008.

Penner, J. E., Andreae, M., Annegarn, H., Andreae, M., Annegarn, H., Barrie, L., Feichter, J., Hegg, D., Jayaraman, A., Leaitch, R., Murphy, D., Nganga, J., Pitari, G., Ackerman, A., Adams, P., Austin, P., Boers, R., Boucher, O., Chin, M., Chuang, C., Collins, B., Cooke, W., DeMott, P., Feng, Y., Fischer, H., Fung, I., Ghan, S., Ginoux, P., Gong, S.-L., Guenther, A., Herzog, M., Higurashi, A., Kaufman, Y., Kettle, A., Kiehl, J., and Koch, D.: Aerosols, their Direct and Indirect Effects, in: Climate Change 2001: The scientific basis, edited by: Houghton, J. T., Ding, Y., Griggs, D. J., Lammel, G., Land, C., Lohmann, U., Madronich, S., Mancini, E., Mishchenko, M., Nakajima, T., Quinn, P. Rasch, P., Roberts, D. L., Savoie, D., Schwartz, S., Seinfeld, J., Soden, B., Tanré, D., Taylor, K., Tegen, I., Tie, X., Vali, G., Van Dingenen, R., van Weele, M., Zhang, Y.: Cambridge University Press, Cambridge, 881 pp., 2001.

Plattner, G. K., Knutti, R., Joos, F., Stocker, T. F., Bloh, W. v., Brovkin, V., Cameron, D., Driesschaert, E., Dutkiewicz, S., Eby, M., Edwards, N. R., Fichefet, T., Hargreaves, S., Jones, C. D., Loutre, M., Mathews, H., Mouchett, A., Muller, S., Nawrath, S., Price, A., Sokolov, A., Strassmann, K., and Weaver, A.: LongTerm Climate Commitments Projected with Climate-Carbon Cycle Models, J. Climate, 21, 2721-2751, 2008.

Prospero, J. and Lamb, P.: African droughts and dust transport to the Caribbean: climate change implications, Science, 302, 10241027, 2003.

Prospero, J., Ginoux, P., Torres, O., Nicholson, S., and Gill, T.: Environmental Characterization of Global sources of atmospheric soil dust derived from the NIMBUS-7 TOMS absorbing aerosol product, Rev. Geophys., 40, 1002, doi:1010.1029/2000RG000095, 2002.

Randerson, J., Hoffman, F., Thornton, P., Mahowald, N., Lindsay, K., Lee, Y.-H., Nevison, C. D., Doney, S., Bonan, G., Stockli, R., Covey, C., Running, S., and Fung, I.: Systematic assessment of terrestrial biogeochemistry in coupled climate-carbon models, Global Change Biol., 15, 2462, doi:2410.1111/j.13652486.2009.01912x, 2009.

Reddy, M., Boucher, O., Belloiun, N., Schulz, M., Balkanski, Y., Dufresne, J., and Pham, M.: Estimates of global multicomponent aerosol optical depth and direct radiative perturbation in the Laboratoire de Meteorologie Dynamique general circulation model, J. Geophys. Res., 110, D10S16, doi:10.1029/2004JD004757, 2005.

Sokolov, A. P., Kicklighter, D. W., Melillo, J. M., Felzer, B. S., Schlosser, C. A., and Cronin, T.: Consequences of considering carbon-nitrogen interactions on the feedbacks between climate and the terrestrial carbon cycle, J. Climate, 21, 3776-3796, 2008.

Steinacher, M., Joos, F., Frlicher, T. L., Bopp, L., Cadule, P., Cocco, V., Doney, S. C., Gehlen, M., Lindsay, K., Moore, J. K., Schneider, B., and Segschneider, J.: Projected 21 st century decrease in marine productivity: a multi-model analysis, Biogeosciences, 7 , 979-1005, doi:10.5194/bg-7-979-2010, 2010.

Stier, P., Feichter, J., Roeckner, E., Kloster, S., and Esch, M.: The 
evolution of the global aerosol system in a transient climate simulation from 1860 to 2100, Atmos. Chem. Phys., 6, 3059-3076, doi:10.5194/acp-6-3059-2006, 2006.

Tagliabue, A., Bopp, L., and Aumont, O.: Ocean biogeochemistry exhibits contrasting responses to a large scale reduction in dust deposition, Biogeosciences, 5, 11-24, doi:10.5194/bg-5-112008, 2008

Taylor, K. E., Stouffer, R. J., and Meehl, G. A.: A summary of the CMIP5 Experimental Design, http://www-pcmdi.llnl.gov/, last access: 2009.

Tegen, I. and Fung, I.: Contribution to the atmospheric mineral aerosol load from land surface modification, J. Geophys. Res., 100, 18, 707-718, 726, 1995.

Tegen, I., Werner, M., Harrison, S. P., and Kohfeld, K. E.: Relative importance of climate and land use in determining present and future global soil dust emission, Geophys. Res. Lett., 31, L05105, doi:05110.01029/02003GL019216, 012004, 2004.

Thornton, P., Lamarque, J. F., Rosenbloom, N. A., and Mahowald, $\mathrm{N}$.: Influence of carbon-nitrogen cycle coupling on land model response to $\mathrm{CO}_{2}$ fertilization and climate variability, Global Biogeochem. Cy., 21, GB4018, doi:10.1029/2006GB002868, 2007.
Thornton, P. E., Doney, S. C., Lindsay, K., Moore, J. K., Mahowald, N., Randerson, J. T., Fung, I., Lamarque, J.-F., Feddema, J. J., and Lee, Y.-H.: Carbon-nitrogen interactions regulate climate-carbon cycle feedbacks: results from an atmosphereocean general circulation model, Biogeosciences, 6, 2099-2120, doi:10.5194/bg-6-2099-2009, 2009.

Woodward, S., Roberts, D., and Betts, R.: A simulation of the effect of climate changed-induced desertification on mineral dust aerosol, Geophys. Res. Lett., 32, L18810, doi:18810.11029/12005GL023482, 2005.

Yoshioka, M., Mahowald, N., Conley, A., Collins, W., Fillmore, D., and Coleman, D.: Impact of desert dust radiative forcing on Sahel precipitation: relative importance of dust compared to sea surface temperature variations, vegetation changes and greenhouse gas warming, J. Climate, 20, 1445-1467, 2007.

Zaehle, S., Friedlingstein, P., and Friend, A. D.: Terrestrial nitrogen feedbacks may accelerate future climate change, Geophys. Res. Lett., 37, L01401, doi:10.1029/2009GL041345, 2010. 